\title{
Optical Imaging in Cancer Research: Basic Principles, Tumor Detection, and Therapeutic Monitoring
}

\author{
Metasebya Solomon $^{a, b} \quad$ Yang Liu ${ }^{a, b} \quad$ Mikhail Y. Berezin ${ }^{a} \quad$ Samuel Achilefu $^{a-c}$ \\ Departments of a Radiology, ${ }^{b}$ Biomedical Engineering and ${ }^{\mathrm{c} B i o c h e m i s t r y}$ and Molecular Biophysics, \\ Washington University School of Medicine, St. Louis, Mo., USA
}

\section{Key Words}

Diffuse optical tomography · Spectroscopy $\cdot$ Molecular probe $\cdot$ Near-infrared $\cdot$ Activatable probes $\cdot$ Image reconstruction $\cdot$ Fluorescence lifetime $\cdot$ Photoacoustic imaging

\begin{abstract}
Accurate and rapid detection of diseases is of great importance for assessing the molecular basis of pathogenesis, preventing the onset of complications, and implementing a tailored therapeutic regimen. The ability of optical imaging to transcend wide spatial imaging scales ranging from cells to organ systems has rejuvenated interest in using this technology for medical imaging. Moreover, optical imaging has at its disposal diverse contrast mechanisms for distinguishing normal from pathologic processes and tissues. To accommodate these signaling strategies, an array of imaging techniques has been developed. Importantly, light absorption, and emission methods, as well as hybrid optical imaging approaches are amenable to both small animal and human studies. Typically, complex methods are needed to extract quantitative data from deep tissues. This review focuses on the development of optical imaging platforms, image processing techniques, and molecular probes, as well as their applications in cancer diagnosis, staging, and monitoring therapeutic response.
\end{abstract}

Copyright $\odot 2011$ S. Karger AG, Basel
(C) 2011 S. Karger AG, Basel

1011-7571/11/0205-0397\$38.00/0

Fax +4161306 1234

E-Mail karger@karger.ch

www.karger.com
Accessible online at: www.karger.com/mpp

\section{Introduction}

The application of optical imaging and spectroscopy in medicine and biomedical research has captivated the attention of many scientists, engineers, and clinicians because of the compactness, low cost, and ability of the technology to provide functional and molecular information $[1,2]$. In the process of optical imaging, light interaction with biological tissues leads to a number of photophysical events such as absorption, scattering, and emission of light. Each of these events can be utilized to obtain biochemical and morphological information about specific cell or tissue of interest. The diverse contrast mechanisms provided by optical methods constitute the basis of several optical imaging platforms that include spectroscopic, planar, diffuse, and hybrid biomedical optics methods [3-6]. In fact, the diversity of imaging and therapeutic platforms available to researchers is a unique strength of optical technology.

Typically, optical imaging begins with the absorption of light by endogenous or exogenous chromophores to provide contrast between diseased and normal surrounding tissue. In absorption imaging, contrast is generated by the differential concentration of the chromophores in tissues $[7,8]$. The absorbed light can dissipate as heat to surrounding tissue, a phenomenon that is useful in photothermal therapy or photoacoustic imaging (PAI) $[5,8]$. 
A fraction of the absorbed light can be reemitted at longer wavelengths than the incident. This emitted light is called autofluorescence if it originates from endogenous chromophores. Autofluorescence is widely used to characterize the metabolic status of tissue. An important example is the classification of tissue as normal or as a benign and malignant tumor based on the optical properties of flavin adenine dinucleotide and reduced nicotinamide adenine dinucleotide (NADH). Autofluorescence imaging and other endogenous fluorophores have an easier path to human translation since the signaling biomolecules are naturally produced by the body. The term fluorescence is generally reserved for light emission generated by exogenous contrast agents. This class of optical imaging platform will be discussed in detail in several sections below. In a variant of fluorescence imaging, spontaneous light emission can be induced by a biochemical reaction, such as the luciferase-catalyzed oxidation of luciferin $[9,10]$. This process is termed bioluminescence. Bioluminescence imaging is widely used to unravel the molecular basis of biochemical processes at the molecular level in cells and small animals. The simplicity of the imaging method, high throughput capability, and the high detection sensitivity and specificity make this approach attractive for drug development, monitoring treatment response, and molecular interactions in animal models of human diseases. Unfortunately, there is no clear path to human translation in the current state of technology due to foreign genetic materials $[9,10]$. In addition to absorption and emission imaging, incident light is highly scattered in heterogeneous media such as tissues. Since the light scattering pattern is dependent on tissue morphology, it is used to generate exquisite structural information of target tissues [6]. For example, the up-regulation or down-regulation of structural proteins such as collagen can be used to report the invasiveness of tumors and the status of wound healing [11].

Beyond cell and small animal studies, the next frontier is the translation of optical imaging and spectroscopy to humans. Major advances have been made in both instrumentation and tissue-targeted molecular probes that are suitable for human use. These advances promise to change the landscape of conventional diagnostic and treatment monitoring methods $[1,4,12-17]$. Interestingly, optical imaging has come a long way from the early days of diaphanography, which used a simple transillumination light scanning method $[18,19]$, to modern-day diffuse optical tomography (DOT) and spectroscopy. Unlike diaphanography, which resulted in poor sensitivity in breast cancer detection (58\%, based on histologic validation of biopsied samples) [20], new techniques have incorporated state-of-the-art imaging algorithms, highly sensitive detectors, and an array of light sources to delineate scattering from absorption parameters. This approach promises to improve both sensitivity and specificity of current imaging systems in clinics. Several optical imaging methods are already used in clinical practice. Notable among these is optical coherent tomography, which furnishes exceptionally high spatial resolution of tissue structure at microscopic level $[21,22]$. The method, which was first introduced for ophthalmologic applications [23], has been expanded to cardiac imaging [24] and cancer diagnosis [25]. Recent studies have also demonstrated the applicability of high-resolution optical fiberbased devices for in vivo characterization of tissues [2628]. Incorporation of this technique into endoscopes will expand their applications to virtually all current endoscopic procedures and enhance the capabilities of intravital microscopy. Thus, in addition to aiding disease diagnosis, optical imaging is anticipated to be effective in monitoring treatment response in cancer patients [2931].

This review focuses on the development of optical imaging platforms, image processing techniques, and molecular probes, as well as their applications for cancer diagnosis, staging, and monitoring therapies. Emphasis is placed on emerging optical methods that are translatable to humans and specific to cancer. As such, bioluminescent and fluorescent proteins are not discussed here. To maintain the focus of this review on imaging, we also excluded light-based cancer treatments such as laser ablation and photodynamic therapy. Mature techniques such as optical coherence tomography are also excluded. Interested readers are referred to comprehensive reviews in bioluminescent protein imaging [10, 32], fluorescent protein imaging [33, 34], photodynamic therapy [15], and optical coherence tomography $[21,22,35,36]$.

\section{Hardware and Image Reconstruction}

Based on the light illumination schemes, optical imaging systems are classified as continuous wave, frequency domain, and time domain imaging methods with planar, reflectance, or cylindrical modes of measurement [3, 4, $16,37-40]$. The continuous wave optical imaging platform illuminates tissues with light of constant amplitude or low frequency modulation and detects the light attenuation caused by differential changes associated with the tissue absorption properties. The frequency domain im- 
Table 1. Comparison of imaging systems techniques

\begin{tabular}{lll}
\hline Continuous wave & Time domain (TD) & Frequency domain (FD) \\
\hline Faster than TD and FD & Quantitative & Quantitative \\
Accurate for differential measurement & High spatial and depth resolution & High spatial and depth resolution \\
of optical properties & Recovery of absorption, fluorescence, and & Faster than TD \\
Relatively compact & scattering properties from temporal impulse & Relatively less expensive than TD \\
Less expensive than TD and FD & response & Recovery of absorption, fluorescence, and \\
& More accurate than FD but slower & scattering properties from diffusive wave \\
& Can be utilized for photoacoustic & Faster than TD but less accurate \\
& methods & Faster than
\end{tabular}

aging platform modulates the light sources at frequencies of tens to hundreds of megahertz and measures the amplitude decay and phase shift of the output light to quantify tissue absorption and scattering properties. The time domain optical platform detects the temporal distribution of diffuse light (photons) after illuminating the tissue with short light pulses for depth-resolved quantification of the tissue's absorption and scattering properties [41-43]. Hybrid imaging methods that utilize light as part of imaging signal generation also use tomographic approaches. For example, in photoacoustic methods, pulsed light is used to generate ultrasound waves from local tissue's thermal expansion following light absorption [44]. Each of these techniques will be described in more detail below. Representative advantages and limitations of the above techniques are summarized in table 1 .

Reconstruction of optical images requires an understanding of the propagation of light in tissue and is largely based on the knowledge of tissue properties that affect photons and the mathematical algorithms to analyze and classify spectral data. These algorithms help to overcome the tissue's high spatial heterogeneity and identify small differences between normal and cancerous tissues. Reconstruction procedure starts from multiple measurements, where an array of light sources and detectors for a defined geometry are used to generate and detect light. Acquisition of experimental data is followed by the application of a light transport model. This model is based on the propagation of photons in the region of interest. It describes the relationship between tissue optical properties (usually absorption and scattering coefficients) associated with the relevant pixels and the resulting sourcedetector measurements [13,45-48]. Light transport in biological tissue is typically modeled stochastically by de- riving probability functions for photon transitions (Monte Carlo, random walk theory) [49] or deterministically by deriving the diffusion equation from radiative transfer equation $[38,46,48,50,51]$. The first method produces more accurate results, but it is computationally demanding. Data analysis can range from several hours to several days of computing. The method based on diffusion equation is faster. Therefore it is used more frequently in clinical setting [52]. In both methods, the light transport model yields a set of dynamic equations describing the transport of photons as a function of optical properties of the tissue and instrument setting.

After establishing the light transport model, the second step in image reconstruction involves finding a solution to a forward problem [37, 45-48]. The forward problem calculates the optical properties of the tissue (absorbance, scattering, or changes in absorption or light attenuation, etc.) as a result of the applied light transport model from step one. Numerical models are commonly used to solve the forward problem and to predict the relationship between the optical parameters for all pixels as a function of the source-detector arrangement. Linear approximations to numerical methods are frequently used to simplify the estimation process $[13,52,53]$. The output of the forward problem is typically presented as a sensitivity matrix, where the values obtained from the forward problem are stored.

In the last step, the image is reconstructed by inverting the sensitivity matrix and solving the inverse problem to recover the optical properties of the tissue $[45,48,51,54]$. To accomplish this goal, the optimization equation is solved to recover the optical properties of the tissue. The procedure is usually based on a least-squares equation (linear or nonlinear) expressing the difference between 
the measured data and the expected measurements obtained from forward problem solution $[55,56]$. This last step has a number of challenges. In general, the inversion of the matrix and the inverse problem solution are illposed because large changes in the model tend to produce only small changes in measurable parameters (real experimental data). Moreover, with the number of pixels larger than the number of measurements, the problem is underdetermined [57]. Both problems can be resolved with additional parameters known as penalty terms. These terms are added to the least-squares equation restricting the solution and enhancing the image. Basic Tikhonov zero-order regularization [58] and more complex functions such as truncated singular value decomposition have been implemented to improve the image quality $[53,56,59]$. The search for the appropriate regularization is in progress in the field of image reconstruction. For detailed information on light transport modeling and image processing, the reader is referred to several extensive reviews on the subject $[37,46]$. In photoacoustic tomography, the image reconstruction also involves the modeling of acoustic waves in tissue. A number of photoacoustic algorithms are described in a recently published book [5].

\section{Optical Imaging Platforms}

This section covers the basic principles of some optical imaging techniques such as planar imaging, diffuse optical spectroscopy (DOS), diffuse optical imaging, and photoacoustic tomography with and without the use of exogenous contrast reagents. The roles of these techniques in clinical detection, staging, and treatment monitoring of tumors are briefly described.

\section{Planar Imaging}

Over the past two decades, optical molecular imaging has benefited from the rapid advances in light sources, detectors, and mathematical modeling techniques. Fluorescence planar imaging is the simplest optical method and it is akin to flash photography. The method is fast and affordable and data analysis is straightforward. The light source required for planar imaging can be as simple as a single white light or a bundle of optical fibers equipped with optical switches [60]. In its simplest form, appropriate filters are used to select the desired excitation wavelengths from a broad spectrum of light sources such as bright light bulbs. More recent versions use continuous wave lasers or light-emitting diodes as the light source to

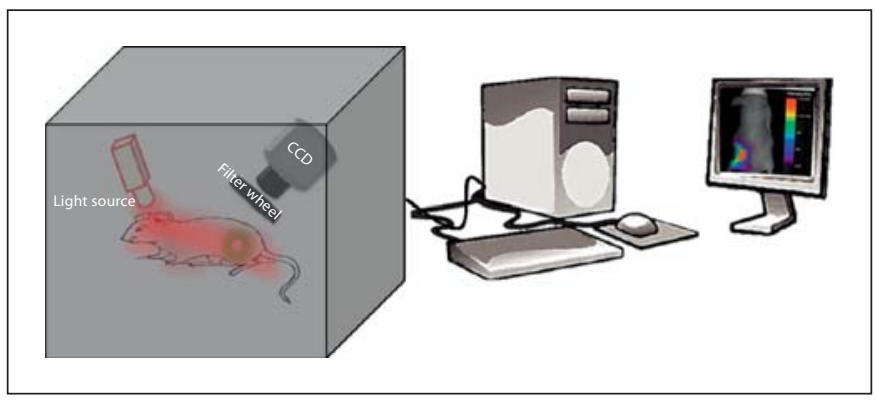

Fig. 1. Schematics of a typical planar reflectance imaging. $\mathrm{CCD}=$ Charge-coupled device.

provide higher power for deep tissue imaging. The ensuing fluorescence is captured with a charge-coupled device camera, the signal is recorded temporally on a computer and displayed on a monitor in near real-time. Planar imaging systems are mostly used to obtain two-dimensional images of tissue in reflectance (epifluorescence) or transmission geometry. The basic components of epifluorescence imaging are shown in figure 1 . In transmission geometry, the detector is placed on the opposite side of the excitation source. Most of the commercially available small animal planar imagers utilize the epi-fluorescence mode because of its simplicity and to overcome problems with attenuation of light in thick tissue.

Normally, the images are generated from the recorded intensity of the emitted light in every pixel of the region of interest. Such images show the location of the target fluorescent molecular probe in tissue. However, the images are surface-weighted, resulting in the loss of quantitative accuracy, depth information and poor spatial resolution caused by scattering of the emitted light. Improvement of the reflectance and transillumination planar imaging methods can be achieved with a data normalization approach [60]. In this technique, the excitation and emission light intensities are acquired sequentially by switching the interference filter between excitation and emission scans. The normalized image is generated by simply dividing the emission light intensity by the excitation light intensity. Phantom and in vivo studies showed that the normalized data improved image quality and accuracy as well as depth sensitivity over a nonnormalized method [60-62].

Further improvement in the depth resolution of planar imaging can be achieved by introducing the phase profilometry technique into the system. The basic principle of phase surface profile characterization (profilometry) is similar to that of tomographic imaging systems. 
Both techniques have depth-sectioning ability from the recovered depth information of the imaging object. Implementation of the phase information recovered from the reflected light for three-dimensional image reconstruction was first implemented by Gabor [63]. In this method, a spatially modulated intensity sine wave is projected onto the object and imaged with a camera from an offset position [64]. The longitudinal distance between a reference plane and the object surface is extracted from the phase distribution at each pixel from multiple sine waves to provide depth information [65]. An alternative approach is to perform a fast Fourier transform using a single intensity sine wave [66]. In a typical arrangement, a light source (profilometer laser) and a detector (profilometer camera) are used to create a phase shift. The laser and camera can be synchronized by tilting the platform to further enhance light penetration depth [65]. Overall, profilometry and triangulation methods produce good-quality three-dimensional images, but this comes at the expense of complex hardware and longer processing time. From an instrumentation and data analysis point of view, these techniques are closer to tomographic systems than to conventional planar imagers.

\section{Diffuse Optical Spectroscopy}

DOS is the most established optical imaging technique for clinical applications. DOS has been widely used to obtain spectrally dependent functional and structural information by extracting absorption and scattering coefficients associated with concentration changes in endogenous and exogenous fluorophores [2, 30, 67-71]. Measurement of hemoglobin absorption in vivo is one of the central approaches in DOS. The absorption spectra of oxy- and deoxyhemoglobin state differ significantly (fig. 2) and the ratio between the two states in tissues is highly conserved. The changes in oxy- and deoxyhemoglobin concentration often indicate tissue abnormality and are frequently used to identify physiological problems and follow the effects of therapy. In a typical setting, DOS systems are mostly composed of a hand-held probe employing a flexiblefiber-based source-detector configuration. Among a variety of DOS techniques, double-differential spectroscopic analysis and diffuse reflectance spectroscopy are the most common. Double-differential spectroscopic analysis of tissue absorption and scattering spectra from 650 to $1,000 \mathrm{~nm}$ has been applied to discriminate normal from cancerous breast tissues [71]. In this method, subtracting the major absorbers' spectral components of normal from cancerous tissues provides patient-specific molecular signature of the tumor, as illustrated in figure 3.

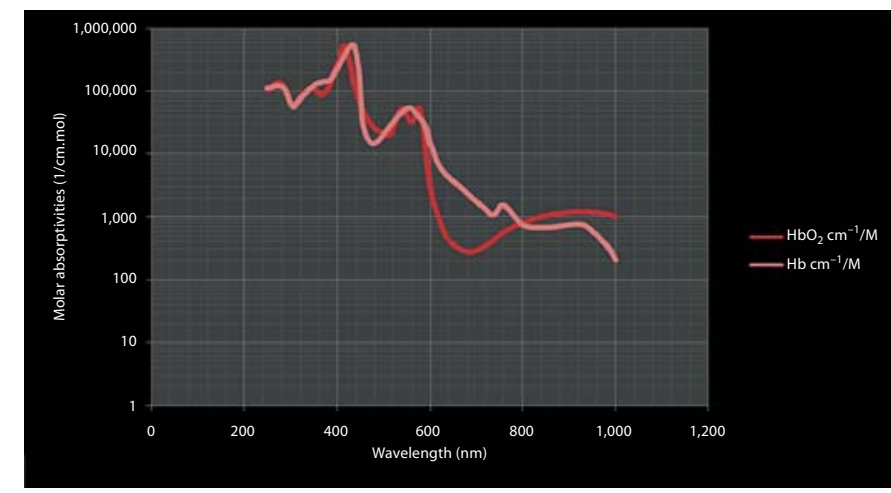

Fig. 2. Absorption spectra for oxygenated and deoxygenated blood. $\mathrm{HbO}_{2}=$ Oxyhemoglobin.

The feasibility of diagnosing tumors and using diffuse reflectance spectroscopy to monitor cancer therapy response by quantifying the associated physiological and morphological changes has also been demonstrated [73]. To accomplish this goal, the authors extracted the concentration of oxy- and deoxyhemoglobin and the scattering coefficient by applying an inverse Monte Carlo model of light transport to diffuse reflectance spectra collected from tumor-bearing mice [73]. A significant increase in the concentration of oxyhemoglobin was observed in doxorubicin-treated animals, which implies that diffuse reflectance spectroscopy can be used to monitor treatment response noninvasively.

Palmer et al. [74] utilized hemoglobin-based DOS to study physiological changes in response to combinational therapy using hyperthermia and liposomal doxorubicin in a murine model. Both diffuse reflectance and fluorescence spectroscopic measurements were performed, allowing multiparametric quantification of optical properties of tissues and fluorescence of the drug doxorubicin. The study demonstrated that the total hemoglobin saturation increased after treatment. In a human study, Cerussi et al. [75] used DOS to evaluate a patient suffering from infiltrating ductal carcinoma. Here, the patient received neoadjuvant chemotherapy consisting of anthracyclines and bevacizumab. Instead of directly comparing the tumor water content and deoxyhemoglobin concentration, a composite tissue optical index, defined as ([deoxyhemoglobin] $\times$ [water])/ [lipids], was used to evaluate responses. A decrease of $\sim 50 \%$ in the index was found in the course of the chemotherapy, indicating high sensitivity of the index to tumors responding to treatment. 


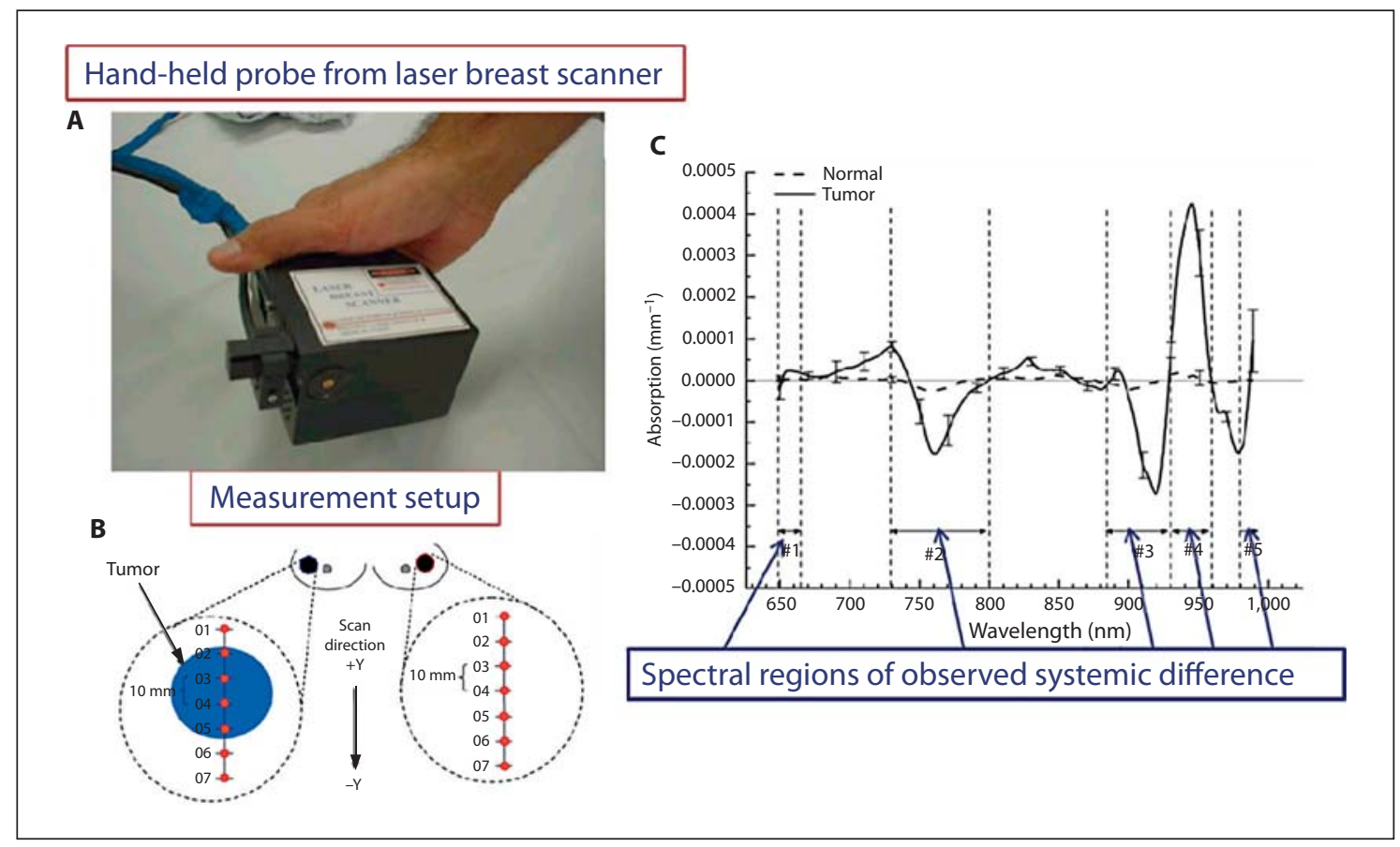

Fig. 3. Optical spectroscopy for primary tumor imaging. A Hand-held probe from laser breast scanner in contact with the breast during data acquisition. B Measurement setup showing the points across line scan. C Graph showing average tumor-specific component-based biochemical and physical property changes such as hemoglobin, oxyhemoglobin, water, and bulk lipid. Reprinted with permission from Kukreti et al. [72].

Overall, the results obtained by different research groups demonstrate the capability of DOS to dynamically monitor tumor-associated physiological and morphological changes noninvasively and use the information to identify patients' response, or lack thereof, to chemotherapy $[29,30,72,76]$.

\section{Diffuse Optical Imaging}

The diffuse optical imaging method is similar to DOS, but it is more complex due to the use of multiple sourcedetector combinations for data acquisition and image reconstruction. Diffuse optical imaging has been used successfully in quantitative studies of the pharmacokinetics and pharmacodynamics of diagnostic and therapeutic agents [40, 43, 62, 76-79].

The DOT method produces three-dimensional images of tissue by combining measurements from multiple sources and detectors with light diffusion modeling techniques for depth localization $[4,37,38,40]$. A variant of diffuse optical imaging systems, fluorescence molecular tomography acquires excitation and emission light intensity profiles sequentially with interference filter switching between two scans [79-81]. A charge-coupled device camera is generally used as a detector in this technique. Sequentially acquired excitation and emission light intensities are used to generate a normalized data set from the emission light intensity profile divided by the excitation light for volumetric reconstruction of fluorescence distribution. Using this approach, Patwardhan et al. [43] developed a fluorescence molecular tomography system capable of whole-body small animal imaging within a few minutes. The system was successfully used to quantify the biodistribution of targeted fluorescent molecular probes in mice bearing subcutaneously implanted human breast carcinoma.

In addition to reporting the fluorescence intensity, optical imaging systems can be modified to quantify fluorescence lifetime. Fluorescence lifetime is an intrinsic property of endogenous and exogenous fluorophores that relates to the average time a fluorophore remains in the excited state before light emission. Advances in laser technology and instrumentation have led to the development of time-resolved imaging techniques for whole-body imaging of cancer in small animals. This trend has aided the growing interest in developing new fluorescence lifetime imaging (FLI) systems for tumor imaging [82-85]. 


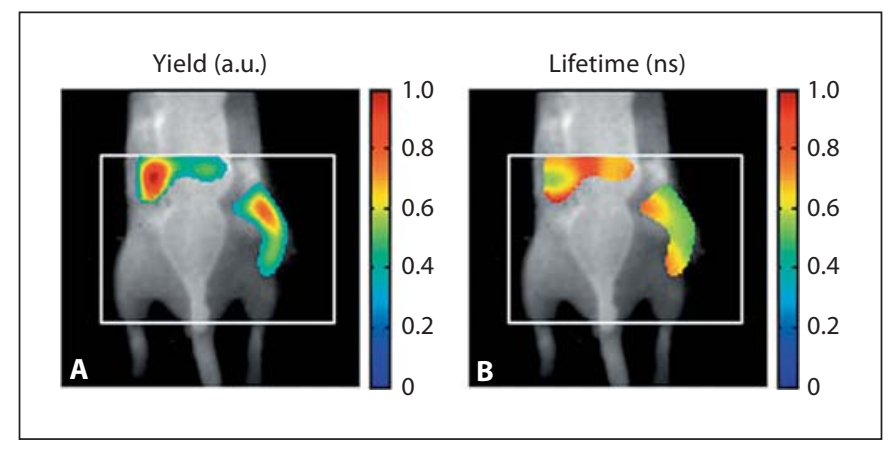

Fig. 4. In vivo imaging with fluorescence molecular tomography. A Fluorescence yield for a tumor-bearing mouse, imaged $24 \mathrm{~h}$ after injection of a targeted agent (cypate-c [RGDfK]). The subcutaneous tumor locates on the right flank along with accumulation in the liver. B Coregistered fluorescence lifetime image from an equivalent vertical slice of a three-dimensional image. The tumor region lifetime is found to be $\tau=0.6 \mathrm{~ns}$. Reprinted with permission from Nothdurft et al. [83].

An important advantage of fluorescence lifetime contrast over fluorescence intensity measurements lies in the fact that it is less dependent on the fluorophore concentration. However, it is generally sensitive to changes in the local tissue environment such as $\mathrm{pH}$, temperature, and presence of fluorescence quenchers $[82-84,86]$. This sensitivity to differences in tissue composition and biochemistry has been used to differentiate cancerous from normal tissues by FLI [82-85]. Cubeddu et al. [87, 88] applied time-domain imaging to localize tumors after fluorescent hematoporphyrin derivative uptake used for photodynamic therapy. The authors treated L1210 leukemia and fibrosarcoma tumors with hematoporphyrin derivative and observed that the fluorescence lifetime was longer in both tumors than in the surrounding normal tissue. This group also demonstrated that FLI can discriminate between normal tissue and basal cell carcinoma in human skin based on the lifetime differences between protoporphyrin IX and normal tissue autofluorescence [89].

Reynolds et al. [90] used the frequency-domain for the lifetime sensitive detection of molecular probes. They extracted and differentiated near-infrared (NIR) contrast agents based on their lifetime differences in tissue-mimicking phantoms. The ability to measure multiple fluorescence lifetimes from several fluorescent probes in a relatively narrow lifetime range (0.5-1.2 ns) demonstrated the potential of FLI in differentiating cancerous from normal tissues. Most in vivo lifetime imaging studies were confined to specialized laboratories until the commercialization of a time-domain lifetime imaging system. Bloch et al. [84] demonstrated the feasibility of using a receptortargeted NIR fluorescence molecular probe (cypate-GRD) for noninvasive whole-body FLI with this commercial system. The study showed selective localization of the tumor based on the probe's lifetime properties. Further tissue analysis showed that the fluorescence lifetime of the molecular probe was $1.03 \mathrm{~ns}$ in tumors and $0.83 \mathrm{~ns}$ in the surrounding tissue. Although the lifetime changes appear to be small, modern FLI systems are capable of resolving 0.1-ns lifetimes, making it possible to potentially detect small but significant physiological changes in tumors.

The development of fluorescence lifetime tomography has further enabled improved temporal resolution and accurate tissue localization up to $1 \mathrm{~cm}$ depth of targeted tumor using fluorescent molecular probes. Nothdurft et al. [83] developed a fluorescence lifetime tomography system that quantitatively resolves fluorescence lifetimes within the narrow range between 0.35 and $1.35 \mathrm{~ns}$ in vivo. In this work, a targeted exogenous NIR optical probe, cypate-c [RGDfk], was injected into a mammary carcinoma mouse model and the fluorescence lifetime map of the whole animal was recorded. The tumor was quantitatively differentiated from the surrounding tissue based on the fluorescence lifetime and intensity maps, as shown in figure 4.

FLI has also enabled imaging of multiple fluorophores with similar absorption and emission spectra but different lifetimes to provide simultaneous information about specific molecular processes without the need for spectral deconvolution of each fluorophore. Reynolds et al. [90], Akers et al. [91], and Raymond et al. [92] were able to recover and separate the distribution of two or/and three NIR fluorescent probes that localized in different organs of mice based on differences in their lifetimes. Their findings suggest that the fluorescence lifetime of different molecular probes can be multiplexed to monitor a variety of molecular interactions through a careful design of NIR fluorescent probes to exhibit lifetime shifts upon target binding. However, one should keep in mind that the difference between individual fluorescence lifetimes must surpass the temporal resolution of the instrument (currently $\sim 100$ ps for tomographic systems) to realize lifetime multiplexing.

\section{Photoacoustic Imaging}

One of the major drawbacks of fluorescence imaging is that it has low spatial resolution in deep tissue imaging due to scattering of excited and emitted light. PAI is a new imaging platform that promises to overcome this major limitation of fluorescence imaging [38, 93-95]. Upon pho- 


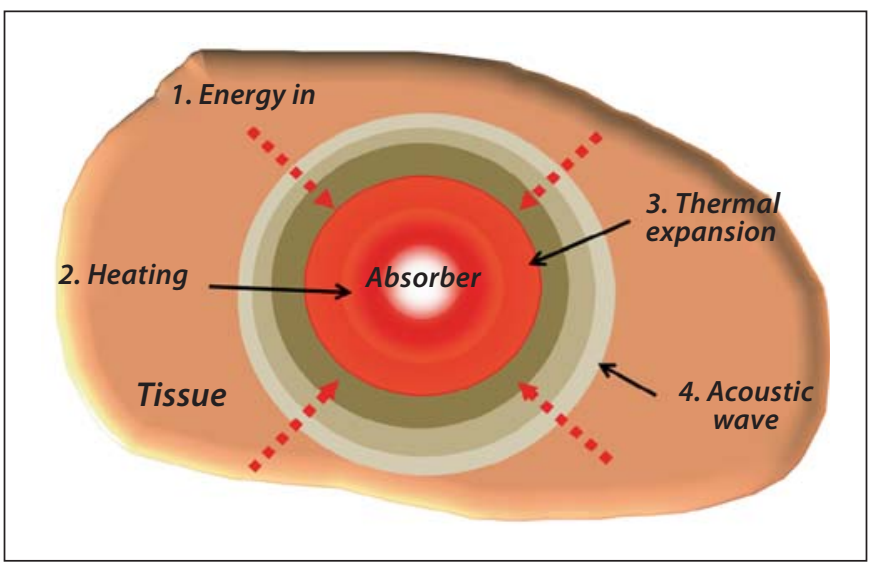

Fig. 5. Generation of the acoustic wave for PAI.

ton absorption by chromophoresin tissue, local heat is produced by nonradiative relaxation of the excited molecules (vibrations). This leads to thermal expansion of the tissue, which produces acoustic waves that are detected by ultrasound transducer. The processes involved in the production of the photoacoustic signal are illustrated in figure 5 . The absorbing molecules can be endogenous pigments, such as hemoglobin, melanin and water, or exogenously delivered optical contrast agents. The produced local heat induces pressure oscillations in the media surrounding the chromophore. The oscillation is further transmitted through a gas, liquid, or solid medium as a travelling wave known as an acoustic pressure or a sound wave. Differential light absorption within a tissue region of interest produces differential heating and, correspondingly, forms acoustic waves with different intensity. The intensities of the acoustic waves propagated through the tissue are used to generate the photoacoustic image. Hence, the image contrast is primarily determined by the different absorption properties of the target tissue.

PAI's spatial resolution as well as depth imaging are mostly dependent on the intensity of the acoustic wave created by photon absorption. The acoustic mean free path in biological tissues is 2-3 orders of magnitude deeper than any optical free path due to lower scattering of ultrasound waves. Hence, the depths at which images can be formed with photoacoustic techniques are inherently greater than those with conventional optical methods. However, this imaging technique also suffers from depth limitation since it relies on light propagation to the target tissue. At certain depths, the effect of light scattering and absorption by tissue decreases the photon flux reaching deep tissue, thereby weakening the acoustic sig-

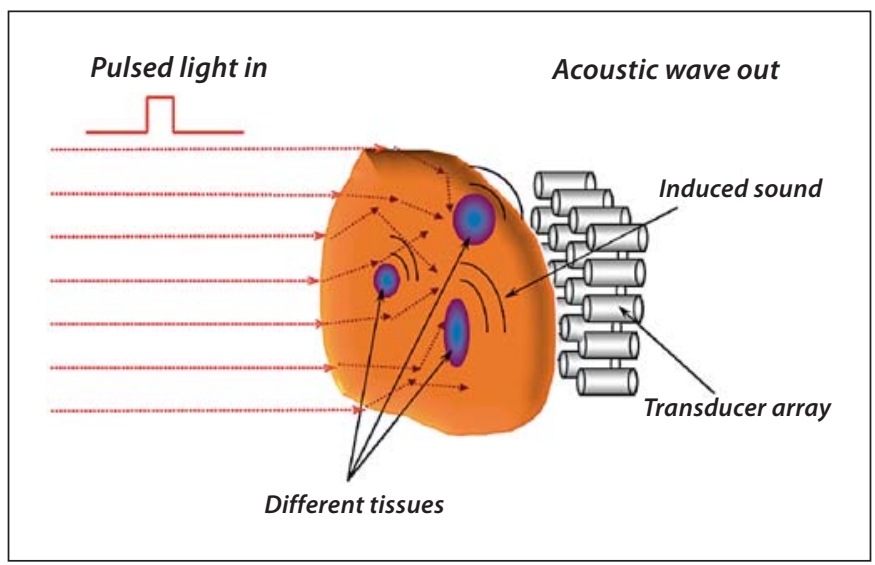

Fig. 6. Illustration of the PAI approach.

nal. Modern photoacoustic instruments can achieve up to $30 \mathrm{~mm}$ depth with $150 \mu \mathrm{m}$ resolution [96]. In addition, cavities and bones with different acoustic properties can distort photoacoustic images.

From the instrumentation standpoint, there are several types of PAI systems. Photoacoustic planar imaging utilizes point-by-point excitation and detection systems and does not require image reconstruction processes to generate an image. In contrast, photoacoustic computed tomography utilizes image reconstruction algorithms. A typical PAI consists of a nanosecond pulsed laser and sensitive microphones or piezotransducers to measure the intensity of the ultrasound waves (fig. 6). The choice of the laser is determined by the absorption properties of the tissue of interest and typically within the range of 530-1,064 $\mathrm{nm}$. For hemoglobin-rich tissues such as blood vessels, 560- to 600-nm lasers are used. Exogenous contrast agents that absorb light in the NIR range $(\sim 700-800 \mathrm{~nm})$ such as cyanine dyes and gold nanoparticles are widely used to enhance contrast in this region where tissue absorption is low [97]. A recent study demonstrated that excitation with $1,064 \mathrm{~nm}$ provides substantial benefit in PAI due to a decreased number of intrinsic light absorbers and the availability of a more homogeneous background signal [98].

The spatial and lateral resolutions of photoacoustic systems are dependent on the type of ultrasound transducer used. An ultrasound transducer with higher central frequency and broader bandwidth is chosen to obtain an improved axial resolution at the expense of signal-tonoise ratio $[95,99]$. The lateral resolution is limited by the focal diameter of the transducer. Photoacoustic techniques can be incorporated in a variety of imaging scanners (fig. 7) for imaging sentinel lymph nodes [100] and 
Fig. 7. In vivo PAI and ultrasound imaging of fluorescent sentinel lymph node. A Control image acquired before injection of nanoparticles. B Photoacoustic image at $3 \mathrm{~h}$ after injection. C Photoacoustic image at $24 \mathrm{~h}$ after injection. A1, B1, C1 B-scan images along the cuts $\mathrm{A} 1, \mathrm{~B} 1$ and $\mathrm{C} 1$, respectively. Reprinted with permission from Akers et al. [100].
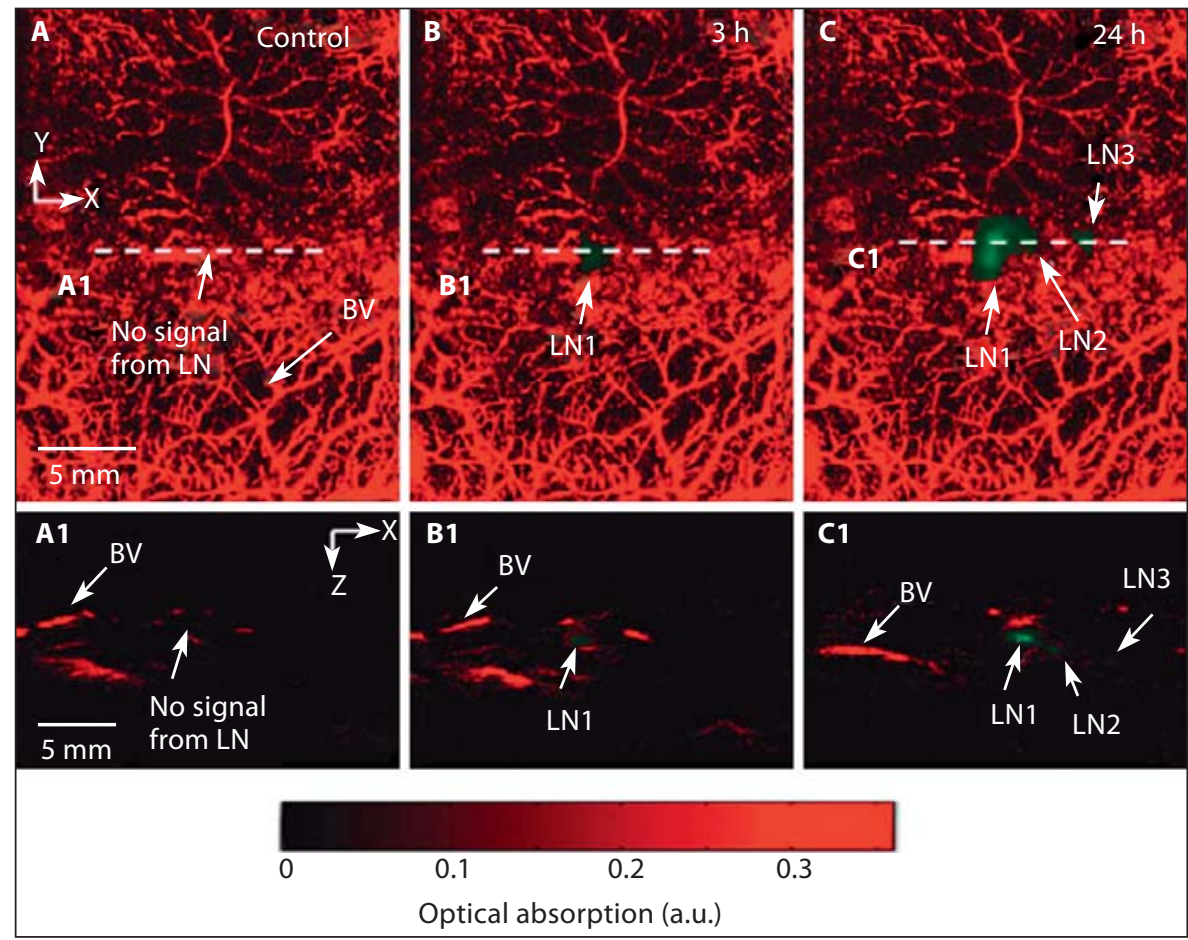

breast cancer [101, 102]. A new hand-held and portable photoacoustic device has been developed for image-guided surgical removal of tumors [103, 104].

PAI has been extensively studied for imaging of cancer without and with contrast agents. For example, due to the rich contrast provided by proliferating blood vessels during angiogenesis and the ability of PAI to resolve these structures, this technique is ideally suitable for imaging angiogenesis $[105,106]$. A review of imaging tumor angiogenesis with PAI has been recently published [107]. For example, melanoma tumor cells were shown to be detected by PAI in blood [108] and brain [105] using the inherent light absorption properties of melanin. PAI has also been successfully used to detect breast and prostate tumors [109], melanoma [110], for noninvasive imaging of sentinel lymph nodes [100, 111-114] and circulating tumor cells [115].

\section{Optical Contrast Agents}

Optical imaging techniques can measure both inherent tissue optical properties (e.g. scattering, absorption and autofluorescence) and those of exogenous molecular probes (e.g. fluorescence, photoacoustic) with high temporal resolution. The spectrally dependent light absorp- tion and propagation properties in tissues (fig. 8) based on optical properties of specific molecules are used to produce imaging contrast in optical molecular imaging. A variety of optical contrast agent-mediated optical methods are widely used for preclinical imaging of cancer and monitoring of therapeutic responses.

\section{Endogenous Tissue Optical Contrast}

Light interaction with biological tissues results in a number of photophysical events such as its absorption and scattering. Scattering is defined as the deviation of a photon path as it propagates through a heterogeneous medium such as a biological tissue. The most useful approximation describing light scattering in tissue is based on Mie's theory $[3,38,68]$. Mie scattering relates to the scattering of light by particles of the same or larger size than the wavelength of the incident light. The intensity of Mie scattered radiation is weakly dependent on wavelength and tissue morphology $[3,38]$. Diffusely reflected and transmitted photons provide diagnostic information about the tissue. For instance, the change in size and number of the major light scatterers in tissue, such as mitochondria and cell nuclei, can be used to differentiate neoplastic from healthy tissues based on the spectral variation of the scattered light. To illustrate this point, the diameter of cell nuclei in normal epithelial tissues 


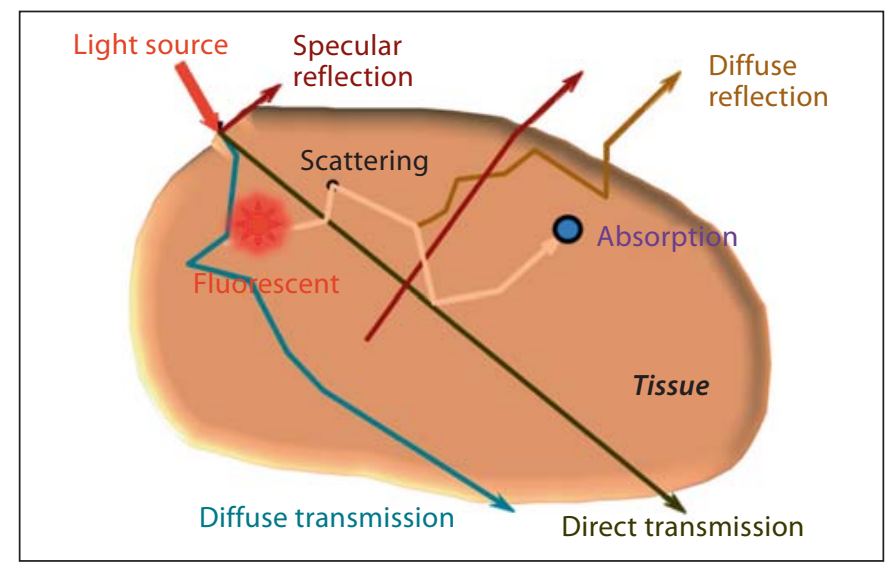

Fig. 8. Light propagation in turbid medium such as biological tissue.

has been found to be approximately $4-7 \mu \mathrm{m}$ compared to $20 \mu \mathrm{m}$ in cancerous tissues, which also contain multiple nuclei $[3,38]$. Hence, scattering properties of tissues provide insight into morphological and structural changes that can be used to identify abnormal variations of the tissue's spatial characteristics. Detailed theoretical basis and practical applications of light scattering in tissues for biomedical imaging have recently been reported [6].

Absorption is a phenomenon that results in the capturing of light energy by chromophores, exciting their electrons from the ground to higher energy levels $[3,4,7$, 38]. The chromophores dissipate their energy in the form of heat or by a radiative decay when their excited electrons return to the ground state $[3,7,38]$. Oxyhemoglobin and deoxyhemoglobin, melanin, myoglobin, and water are the predominant endogenous absorbers in the 600- to $1,000-\mathrm{nm}$ range. Interestingly, the absorption coefficients of these chromophores are low between 700 and $900 \mathrm{~nm}$ relative to the visible wavelengths, creating an optimal spectral window that allows light to travel in deep tissue and the photons to undergo multiple scattering events before attenuation $[3,38,68]$. For these reasons, most optical methods for deep tissue imaging and DOT in particular operate in this 'transparent optical window'.

As mentioned above, variations in total hemoglobin and oxygen saturation can be inferred from tissue absorption based on the differences in oxyhemoglobin and deoxyhemoglobin optical spectra. For tumor imaging, a high level of $\mathrm{HbO}_{2}$ may suggest an increase in arterial blood supply, creation of new blood supply pathways to tumors, or high metabolic oxygen demand reminiscent of highly proliferating tumors. In contrast, an increase in deoxyhemoglobin concentration implies a decrease in oxygen saturation associated with the presence of a hypoxic tumor or high oxygen extraction. Both $\mathrm{HbO}_{2}$ and deoxyhemoglobin serve as important biomarkers for tumor diagnosis and monitoring the outcome of a therapeutic intervention. To illustrate this approach, Choe et al. [29] demonstrated the feasibility of localizing invasive breast carcinoma with DOT by quantifying the total hemoglobin and oxyhemoglobin concentrations. The authors observed that the tumor volume and total hemoglobin concentration decreased from $21.4 \pm 1.4$ to $9.1 \pm 0.5$ $\mu \mathrm{M}$ over the course of the chemotherapy (fig. 9). A variety of similar studies has been reported and a recent paper by Leff et al. [116] summarized the findings of optical-based breast imaging studies from different research groups.

Tissue autofluorescence occurs when excited electrons of endogenous fluorophores emit light of different wavelength after photon absorption $[3,38,85]$. The importance of autofluorescence for studying cells and tissues lies mostly in their potential for diagnostic applications. It is also used as a research tool to understand the underlying mechanisms of molecular interactions and signaling processes under their native conditions $[68,85,117]$. The most important fluorophores for autofluorescence in cells and tissues are amino acids (phenylalanine, tyrosine and tryptophan), which are the essential building blocks of proteins and enzymes; nicotinamide and flavins, which regulate cell metabolism; porphyrins, which are responsible for the transport of respiratory gases; structural proteins (collagen and elastin), which are responsible for rigidity and flexibility of tissues and organs, and fluorescent pigments (melanin, lipofuscin), which are markers of many age-related pathologies [85, 117]. For instance, endogenous fluorophores such as flavin adenine dinucleotide and reduced NADH are used to monitor changes in the metabolic level of tissues by taking the ratio of their fluorescence intensity obtained from one- and two-photon confocal microscopy [68] as well as with diffuse spectroscopy [118]. The fluorescence intensity of $\mathrm{NADH}$ is found to be higher than that of its oxidized form (NAD+), and vice versa for flavin adenine dinucleotide. However, a number of challenges associated with the complex nature of autofluorescence, such as weak fluorescence signals, the use of damaging UV light or high-power two-photon visible excitation, and difficulties in interpretation of images, limit its broad applications in molecular imaging and disease diagnosis. Thus, the use of autofluorescence depends on the intended application or tissue type. For example, skin diseases and a 
A

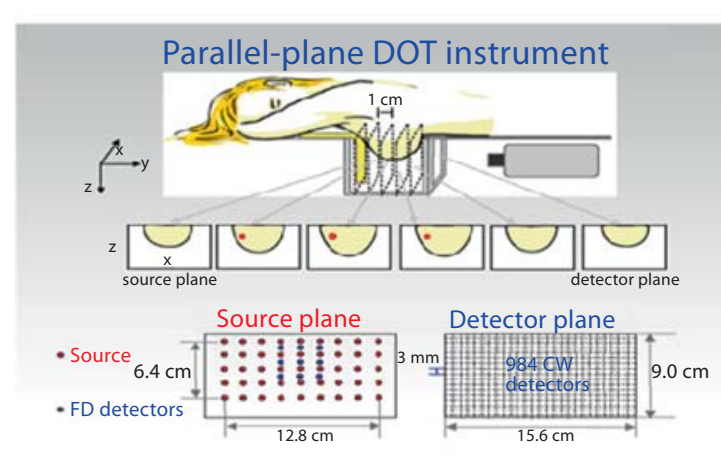

B

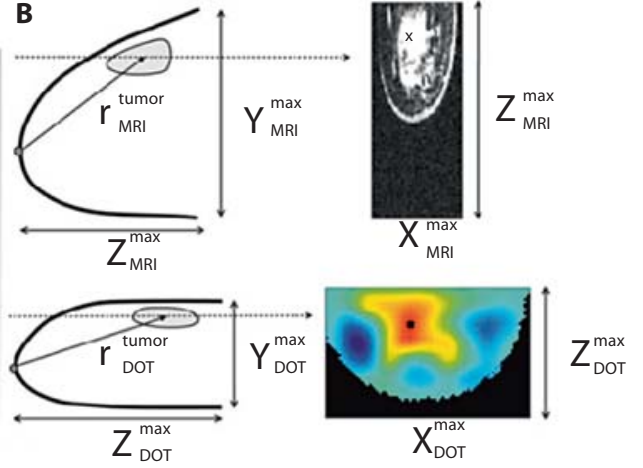

C

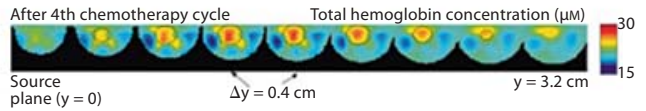

Fig. 9. Breast tumor imaging and chemotherapy monitoring. A DOT instrument. B DOT-reconstructed breast image compared to MRI image. C DOT was used for tracking progress of a female patient with breast cancer during neoadjuvant chemotherapy. The reconstructed hemoglobin concentration and tumor volume shows a decrease after each chemotherapy session. Reprinted with permission from Choe et al. [29].

variety of endoscope-based applications that do not require deep tissue analysis have benefited from autofluorescence imaging. Exciting studies using endoscopes for examining gastrointestinal neoplasia in clinical settings have been reported $[119,120]$. Note that fluorophores from diet also contribute significantly to autofluorescence. This type of autofluorescence could increase background signals during tissue imaging with exogenous imaging agents. However, several methods are available to minimize this side effect, including fasting the animal, the use of special diet with low autofluorescence, and techniques to spectrally suppress autofluorescence $[121,122]$.

\section{Exogenous Tissue Contrast Agents}

Exogenous contrast agents are playing a crucial role in advancing optical molecular imaging for a wide array of applications, ranging from studying cell regulation mechanisms to cancer diagnosis. The advantage of exogenous optical contrast agents lies in the ability to optimize their structure for a wide variety of disease-specific studies. This is generally accomplished by tuning their spectral properties. Optical probes that absorb and emit in the visible spectral range are mainly used for superficial tissue imaging (for example skin cancer detection) and studies of cell mechanisms. However, the signal obtained from optical probes in the visible range is biased by background tissue autofluorescence signal, which is negligible in the NIR spectral range. Therefore, molecular probes in the NIR region are primarily used for deep tissue in vivo imaging and to minimize autofluorescence. Optical contrast agents are classified into different groups based on their fluorophore structure, spectral range, and specific activity. Examples of common optical probes are cyanine dyes, boron-dipyrromethene-based molecules, and quantum dots $[85,123]$. The sources of contrast could be due to change in intensity, fluorescence lifetime or polarization associated with biological processes. Preferably, optical molecular probes should have high molar absorptivity, high fluorescence quantum yield (for fluorescence imaging), and good photostability. For activatable probes, they should preferably be enzymatically stable to nontarget enzymes and biochemical reactions. In addition, chemical stability is important for a new generation of molecular probes carrying targeting groups for selective delivery to tumors. Such targeted conjugates further enhance the sensitivity and specificity of optical contrast agents for early detection of cancer.

\section{Nontargeted Optical Contrast Agents}

Nontargeted optical contrast agents typically accumulate in tumors because of increased tumor vascularization and/or leaky blood vessels [12, 99, 124, 125]. The approved use of the NIR fluorescent dye indocyanine green (ICG) by the US Food and Drug Administration for non- 
imaging indications has allowed its adoption as a nonspecific and biocompatible optical imaging agent in humans. Thus, indocyanine is widely used to test the performance and specifications of optical imaging devices in clinical and preclinical studies. It is also used as a generic imaging agent for cancer imaging. For example, Intes et al. [126] localized suspicious masses in breast cancer patients after bolus administration of ICG. Additionally, Alacam et al. [127, 128] introduced a computational model to analyze ICG pharmacokinetics in cancerous tumors versus normal tissues using NIR DOT. In these studies, the authors provided temporal images of the distribution of ICG from breast cancer patients. Using a computational model, they reported significant differences in the pharmacokinetic rates as well as ICG concentration in the tumor compared to the surrounding normal tissue region. Recently, Sevick-Muraca et al. [129] demonstrated the feasibility of employing NIR fluorescence imaging for dynamic lymph trafficking and lymph node mapping in humans noninvasively after bolus injection of ICG in the arms and legs of patients. The impressive dynamic images demonstrated the potential of using optical molecular imaging for sentinel lymph node mapping in cancer staging. However, since nontargeted optical probes suffer from low selectivity for tumors, the use of molecular probes that selectively target cancer tissue, could further improve the information content obtained, particularly in the identification of positive nodes for biopsy.

\section{Cancer Biomarkers and Targeted Probes}

Many of the current efforts in tumor imaging have focused on the design of cancer-targeting molecular probes. One approach is to identify cancer biomarkers, such as overexpressed proteins or diagnostic enzymes in the tumor and the appropriate molecule (ligand) that binds to a target biomarker with high affinity. Once the biomarkers and the ligands are established, the targeted molecular probe can be prepared by conjugating the targeting moiety to the dye. Cancer biomarker identification is essential for early diagnosis, prognosis and staging of cancers as well as monitoring and optimizing therapies. In general, cancer biomarkers for targeted optical imaging are biomolecules such as cell surface protein receptors or enzymes, which are overexpressed in the active form in neoplasms compared to normal tissues. Many of these biomarkers are commonly shared by a number of malignant tumors $[130,131]$. Below we review two classes of molecular-targeted probes: nonactivatable and activatable.

Optical imaging with receptor-targeted molecular probes relies on the increased concentration of the probe on the target tissue to generate increased optical (fluorescence or photoacoustic) signal. Historically, this was the first type of tumor-targeted molecular probes [132]. Today, a majority of the tumor-targeting molecular probes belongs to this class and a large number of constructs are now commercially available.

Initial studies relied on the labeling of large biomolecules such as antibodies for optical imaging $[133,134]$. These pioneering studies gave rise to highly promising advances in the molecular imaging of tumors. For example, the transmembrane tyrosine kinase receptor proteins of which a member of the epidermal growth factor receptor family, the human epidermal growth factor receptor 2 (HER-2/neu), is commonly overexpressed, have become a favorite target for optical imaging of tumors. The key function of the epidermal growth factor receptor is intracellular signal transduction to control cell proliferation, migration and cell survival [135-137]. Up-regulation of HER-2/neu has been associated with tumor growth and metastasis [135, 138]. Trastuzumab (also known as Herceptin) is a humanized monoclonal antibody that has high affinity for HER-2 receptors $[139,140]$. Therefore, a number of efforts in optical imaging of cancer involved conjugating fluorescent dyes with trastuzumab to image HER-2-positive tumors [141, 142].

Although large proteins and antibodies hold great promise for the development of tumor-targeting agents with high binding affinity to the target receptor, interest in the use of small peptide-based molecular probes has continued to gain ground in receptor-targeting imaging platforms. A prominent example is the targeting of somatostatin receptors with fluorescent dye-labeled somatostatin peptide analogues such as octreotate [124, 143]. The somatostatin receptor served as a target in a whole-body animal imaging study with a receptor-targeted NIR fluorescent probe. In this example, a NIR fluorescent dye analogue to ICG but with conjugatable functionalities, cypate, was covalently linked to octreotate. Using a planar fluorescence reflectance imaging system, the in vivo distribution of the molecular probe in rodents bearing pancreatic acinar carcinomas was obtained [132]. The high uptake of the optical molecular probe in the tumor is demonstrated in figure 10. Since this pioneering study, numerous studies have validated the use of NIR dye-labeled peptides to image tumors in living systems as described below.

Other examples of a cancer biomarker that is overexpressed in a wide range of tumors are the $\alpha v \beta 3$ integrins, which are heterodimeric cell surface proteins composed 
Fig. 10. Structure of cypate-octreotate imaging agent $(\mathbf{A})$ and fluorescence images of pancreatic tumor-bearing rat at $1 \mathrm{~min}(\mathbf{B})$, $45 \mathrm{~min}(\mathbf{C})$ and $27 \mathrm{~h}(\mathbf{D})$ after injection of the optical probe. Ex vivo fluorescence image of representative major organs (E) shows fluorescence intensity of excised organs tissue. Modified figure reprinted with permission from Achilefu [12].

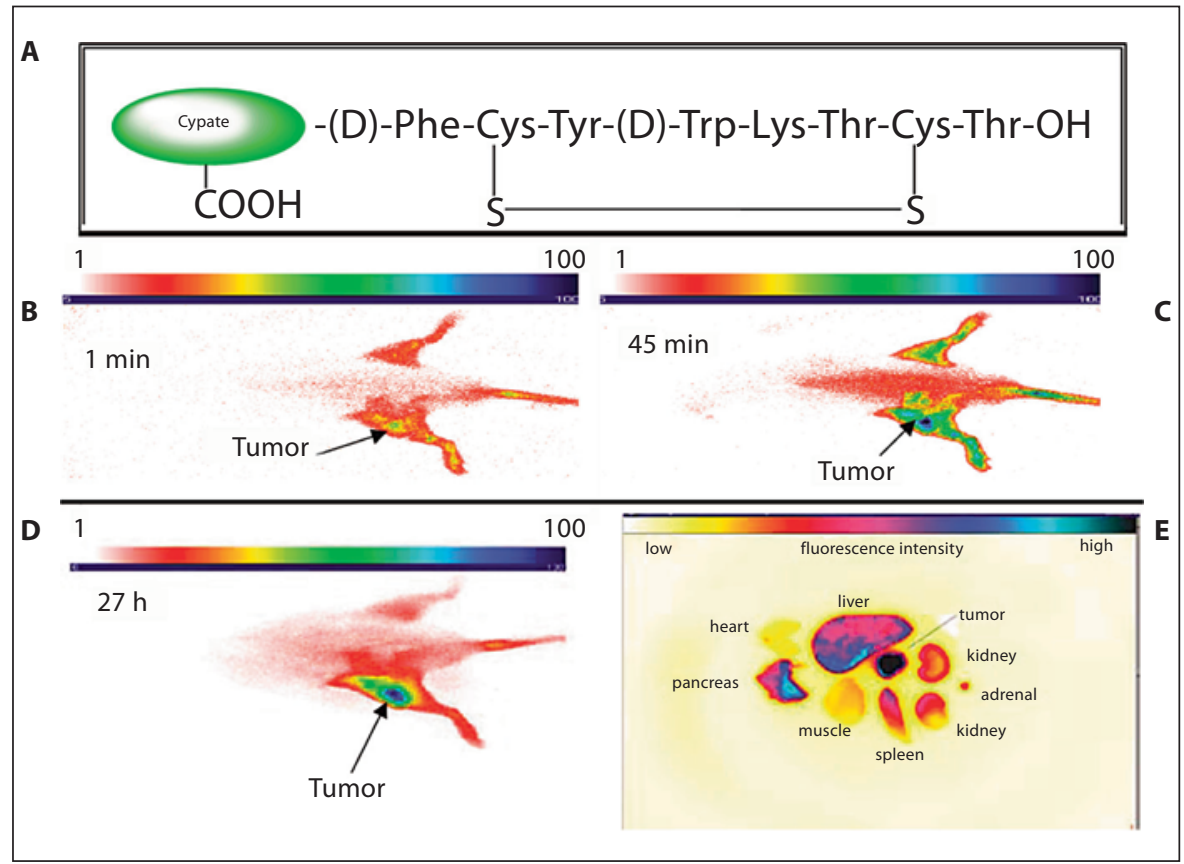

of one $\alpha$ and one $\beta$ transmembrane glycoprotein subunit [144]. The key function of integrins is to regulate multiple intracellular signal transduction pathways leading to cell proliferation, differentiation, migration and survival [144-146]. The $\alpha \mathrm{v} \beta 3$ integrin is of special interest because it is up-regulated in various tumors as well as angiogenic blood vessels $[145,147]$. The $\alpha v \beta 3$ integrin has high affinity for the naturally occurring proteins/polypeptides possessing Arg-Gly-Asp (RGD) peptide sequence [148]. The utility of an NIR fluorescent probe decorated with RGD peptides in tumor imaging has been reported by many investigators [12, 149-152]. Achilefu et al. [150] also discovered that a variant of RGD peptides possessing the GRD peptide sequence labeled with cypate selectively accumulates in $\alpha \mathrm{v} \beta 3$ integrin-positive tumor (A549) in nude mice. The study was conducted with a simple planar fluorescence reflectance imaging system. Further microscopic analysis showed that retention of this molecular probe in the tumor correlated with regions of high expression of metabolic indicators such as NADH. Thus, this molecular probe appears to selectively target highly proliferating tumors.

Following the success of preclinical studies, efforts to move the receptor-targeted optical imaging to humans have increased recently. The highly compartmentalized nature of the gastrointestinal system and the ease of accessing this organ with endoscopes have attracted the first human study of molecular optical imaging of gastrointestinal tumors with a peptide-based exogenous imaging agent [153]. The fluorescein-conjugated peptide construct was developed to bind more strongly to dysplastic colonocytes than to adjacent normal cells and demonstrated $81 \%$ sensitivity and $82 \%$ specificity. Applications of this approach for image-guided intraoperative procedures are also in progress.

Targeted activatable optical contrast agents are mostly designed to interrogate biological processes associated with abnormal protease activities and tissue metabolism. Activatable probes are generally composed of a covalently linked fluorophore pair with different or similar optical properties in close proximity to each other. For the Förster or fluorescence resonance energy transfer (FRET) mechanism, the emission spectrum of the donor must overlap with the absorption spectrum of the acceptor [85]. In this configuration, the transmission of the excitation energy from the donor to the acceptor dye quenches the fluorescence of the donor [85], decreasing the donor's fluorescence intensity and lifetime. Upon enzymatic cleavage, the two fluorophores separate from each other, resulting in an increase of the donor's fluorescence intensity and lifetime. The amount of energy transfer measured from the fluorescence intensity and fluorescence lifetime of the activatable optical probes can be used to investigate changes in biological processes [82]. The pro- 


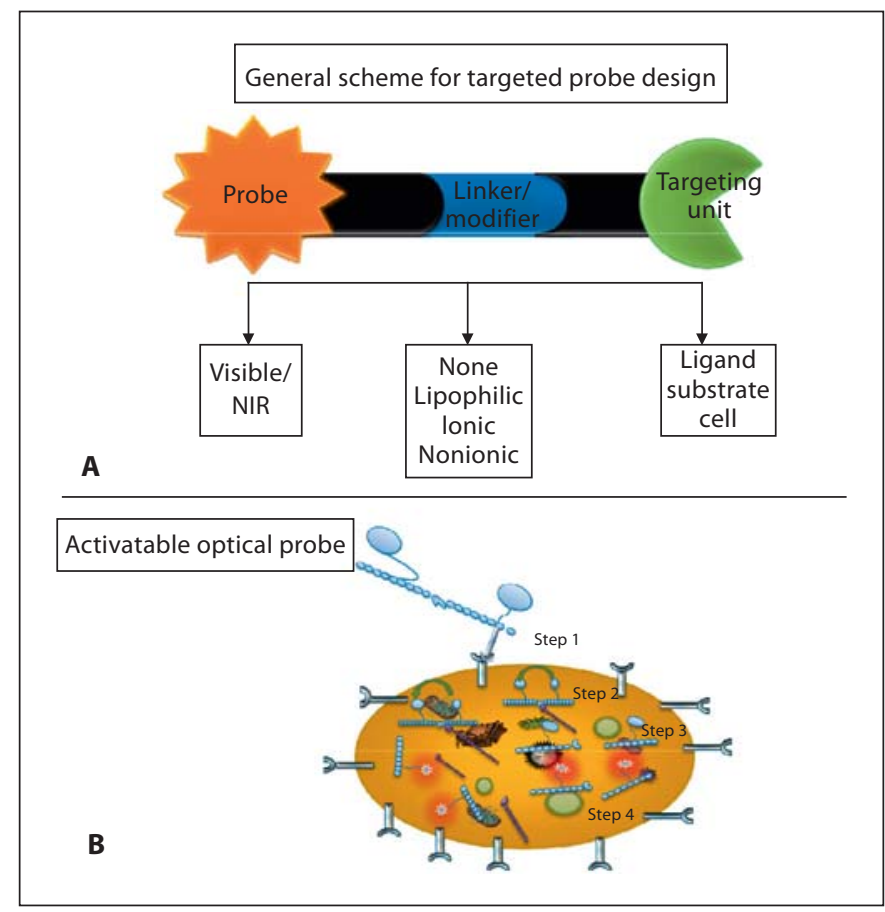

Fig. 11. Schematic design of targeting nonactivatable optical probe $(\mathbf{A})$ and process of utilizing targeted activatable FRET probe (B). Step 1: Internalization of protease activatable molecular probe via a membrane receptor. Step 2: Transmission of excitation energy from donor to acceptor dye quenches the fluorescence of donor. Steps 3 and 4: Recovering fluorescence after releasing quencher moiety when probe binds to active site of diagnostic enzymes.

cess of FRET probe activation and application in tumor imaging is illustrated in figure 11. A number of FRET probes including those optically active in NIR were designed to recover fluorescence after releasing the quencher moiety, which occurs when the probe binds to the active site of diagnostic enzymes [154-159].

Abnormally high proteolytic activities of extracellular and intracellular proteases such as matrix metalloproteinase (MMP), cathepsin and caspase families are found to mediate tumor growth, invasion, and metastasis [155, $156,160,161]$. Particularly, MMPs and cathepsin families are involved in basement membrane degradation, leading to local cell invasion and metastasis $[162,163]$. The utility of the protease-activatable probes for in vivo tumor imaging was first demonstrated by Weissleder et al. [164]. They developed activatable NIR fluorescent molecular probe to localize lung tumor and image the expression and activity of lysosomal proteases. Bremer et al. [165, 166] used this strategy to image the expression and activity of MMP-2 enzymes in vivo. The study showed recov- ery of fluorescence after injection of the probe in mice bearing MMP-2-positive human fibrosarcomas. Fluorescence signal from the nonspecific control molecular probe was minimal. These and other activatable molecular probes have improved the detection sensitivity of tumors in animal models.

In addition to MMPs, other biomarkers have also been targeted as tumor reporters and for monitoring treatment responses. For example, Blum et al. [167] developed molecular probes that could monitor cathepsin B activity, which mediates tumor invasion, and Gocheva et al. [168] utilized fluorogenic peptides for neoangiogenesis detection. These studies were conducted with in vivo mouse models of human epithelial adenocarcinoma and pancreatic islet cell carcinogenesis, respectively.

Another area of intense research is to monitor treatment response through cell death using activatable probes. Programmed cell death, known as apoptosis, is partly controlled by intracellular caspases. These enzymes are up-regulated in cells undergoing apoptosis and studies have shown that disruption of apoptosis results in abnormal cell proliferation and tumor growth. The activities of these proteolytic enzymes have been recognized as important markers for developing imaging and therapeutic agents to noninvasively monitor tumor progress and therapy response $[158,169,170]$. For instance, Bullok et al. [171, 172] developed a FRET-based caspaseactivatable molecular probe, TcapQ647, composed of a fluorescent moiety in close proximity to a NIR fluorescent quencher linked with a caspase-cleavable peptide sequence. The study demonstrated the utility of TcapQ647 for imaging amoeba-induced cell death in mice with colon xenografts. They observed a greater increase in parasite-infected xenografts versus controls after TcapQ647 injection, thus demonstrating the potential of the compound for monitoring treatment response. An example of caspase-3-activatable probes that are based on FRET between two NIR cyanine dyes connected with a caspase-3cleavable peptide substrate, Asp-Glu-Val-Asp (DEVD), was designed by Zhang et al. [158]. Upon contact with caspase-3, whose overexpression was induced by the administration of the chemotherapeutic drug (paclitaxel) to A549 tumor-bearing mice, cleavage of the DEVD peptide sequence in the fluorescence-quenched probe resulted in fluorescence restoration.

Although activatable molecular probes have improved the detection sensitivity of tumors in vivo by lowering background fluorescence, they suffer from nonspecific activation in the blood and healthy tissues. Therefore, the development of highly sensitive and specific activatable 
molecular probes for tumor imaging is an active area of current research endeavors. Efforts to translate some of the probes to humans have been initiated by different research groups.

\section{Future Work and Perspectives}

Early diagnosis of cancer and development of nearreal-time monitoring of tumor response to therapy are needed to improve the outcome and the quality of life for cancer patients. In the last decade, powerful diagnostic methods such as positron emission tomography (PET), computed tomography (CT), magnetic resonance imaging (MRI), and ultrasound imaging have revolutionized the course of medicine in general and oncology in particular. Medically useful information from these methods could be further augmented by combining them with optical imaging for early cancer screening, guided biopsies and monitoring therapies. Such multimodal imaging would allow the combination of structural information traditionally obtained with established CT, MRI and ultrasound techniques with functional and molecular information provided by optical imaging $[69,173-$ 178]. However, extensive research is still required to develop multimodal optical contrast agents, integrate hardware and mathematical algorithms to achieve this goal.
Recently published multimodal molecular imaging probes for single-photon emission computed tomography (SPECT)/optical [179], PET/optical [154, 180, 181], and MRI/optical [182] are promising candidates for multimodal imaging. One of these probes is based on ${ }^{64} \mathrm{Cu}$ NIR dye conjugated to caspase-3 substrate [154], where the PET radionuclide component is used to localize and quantify probe distribution, while NIR dye helps to monitor the activity of caspase-3 enzyme in vivo.

Hardware integration requires compatibility of all the parts on one platform for accurate coregistration of multimodal three-dimensional images enhanced by single multimodal contrast agent to improve cancer detection and therapeutic monitoring. One of the main challenges in combining imaging modalities is determining how to merge the information from multiple technologies into a single imaging output. Part of this complexity arises as a result of the sensitivity of each modality to different sets of tissue properties and methods have disparate reporting strategies. This is currently a subject of intensive research with several groups developing algorithms for incorporating structural information from X-ray/CT [179, 183] and MRI [177], with DOT reconstruction algorithm.

Overall, optical molecular imaging has the potential to become a powerful and practical tool for a wide array of applications such as noninvasive early detection, image-guided biopsies and intraoperative procedures, and therapeutic monitoring of cancer.

\section{References}

1 Hebden JC, Arridge SR, Delpy DT: Optical imaging in medicine. I. Experimental techniques. Phys Med Biol 1997;42:825-840.

2 Sokolov K, Follen M, Richards-Kortum R: Optical spectroscopy for detection of neoplasia. Curr Opin Chem Biol 2002;6:651-658.

3 Tuchin VV: Tissue optics: light scattering methods and instruments for medical diagnosis, ed 2. Bellingham, SPIE Publications, 2007.

4 Vo-Dinh T: Biomedical Photonics Handbook. Boca Raton, CRC Press LLC, 2003.

5 Wang LV: Photoacoustic imaging and spectroscopy. Boca Raton, CRC, 2009.

6 Wax A, Backman V: Biomedical applications of light scattering. New York, McGraw-Hill, 2010.

7 Niemz MH: Laser-tissue interactions: fundamentals and applications, ed 3 enlarged. Berlin, Springer, 2003.

8 Knappe V, Frank F, Rohde E: Principles of lasers and biophotonic effects. Photomed Laser Surg 2004;22:411-417.
9 O’Neill K, Lyons SK, Gallagher WM, Curran KM, Byrne AT: Bioluminescent imaging: a critical tool in pre-clinical oncology research. J Pathol 2010;220:317-327.

10 Dothager RS, Flentie K, Moss B, Pan MH, Kesarwala A, Piwnica-Worms D: Advances in bioluminescence imaging of live animal models. Curr Opin Biotechnol 2009;20:4553.

11 Yeh AT, Kao BS, Jung WG, Chen ZP, Nelson JS, Tromberg BJ: Imaging wound healing using optical coherence tomography and multiphoton microscopy in an in vitro skinequivalent tissue model. J Biomed Opt 2004; 9:248-253.

12 Achilefu S: Lighting up tumors with receptor-specific optical molecular probes. Technol Cancer Res Treat 2004;3:393-409.

13 Arridge SR: Optical tomography in medical imaging. Inverse Problem 1999;15:R41-R93.
14 Arridge SR, Hebden JC: Optical imaging in medicine. II. Modelling and reconstruction. Phys Med Biol 1997;42:841-853.

15 Celli JP, Spring BQ, Rizvi I, Evans CL, Samkoe KS, Verma S, Pogue BW, Hasan T: Imaging and photodynamic therapy: mechanisms, monitoring, and optimization. Chem Rev 2010;110:2795-2838.

16 Erickson SJ, Godavarty A: Hand-held based near-infrared optical imaging devices: a review. Med Eng Phys 2009;31:495-509.

17 Gibson AP, Hebden JC, Arridge SR: Recent advances in diffuse optical imaging. Phys Med Biol 2005;50:R1-R43.

18 Monsees B, Destouet JM, Gersell D: Light scan evaluation of nonpalpable breast lesions. Radiology 1987;163:467-470.

19 Monsees B, Destouet JM, Totty WG: Light scanning versus mammography in breast cancer detection. Radiology 1987;163:463-465.

20 Drexler B, Davis JL, Schofield G: Diaphanography in the diagnosis of breast-cancer. Radiology 1985;157:41-44. 
-21 Huang D, Swanson EA, Lin CP, Schuman JS, Stinson WG, Chang W, Hee MR, Flotte T, Gregory K, Puliafito CA, Fujimoto JG: Optical coherence tomography. Science 1991;254: 1178-1181.

-22 Boppart SA, Luo W, Marks DL, Singletary KW: Optical coherence tomography: feasibility for basic research and image-guided surgery of breast cancer. Breast Cancer Res Treat 2004;84:85-97.

-23 Swanson EA, Izatt JA, Hee MR, Huang D, Lin CP, Schuman JS, Puliafito CA, Fujimoto JG: In-vivo retinal imaging by optical coherence tomography. Opt Lett 1993; 18:18641866.

-24 Bezerra HG, Costa MA, Guagliumi G, Rollins AM, Simon DI: Intracoronary optical coherence tomography: a comprehensive review clinical and research applications. JACC Cardiovasc Interv 2009;2:1035-1046.

25 Tearney GJ, Brezinski ME, Bouma BE, Boppart SA, Pitris C, Southern JF, Fujimoto JG: In vivo endoscopic optical biopsy with optical coherence tomography. Science 1997;276 2037-2039.

-26 Badizadegan K, Backman V, Boone CW, Crum CP, Dasari RR, Georgakoudi I, Keefe K, Munger K, Shapshay SM, Sheets EE, Feld MS: Spectroscopic diagnosis and imaging of invisible pre-cancer. Faraday Discuss 2004; 126:265-279.

-27 Flusberg BA, Cocker ED, Piyawattanametha W, Jung JC, Cheung ELM, Schnitzer MJ: Fiber-optic fluorescence imaging. Nat Methods 2005;2:941-950.

28 VoDinh T, Panjehpour M, Overholt BF, Buckley P: Laser-induced differential fluorescence for cancer diagnosis without biopsy. Appl Spectrosc 1997;51:58-63.

29 Choe R, Corlu A, Lee K, Durduran T, Konecky SD, Grosicka-Koptyra M, Arridge SR, Czerniecki BJ, Fraker DL, DeMichele A, Chance B, Rosen MA, Yodh AG: Diffuse optical tomography of breast cancer during neoadjuvant chemotherapy: a case study with comparison to MRI. Med Phys 2005;32: 1128-1139.

30 Kukreti S, Cerussi AE, Tanamai W, Hsiang D, Tromberg BJ, Gratton E: Characterization of metabolic differences between benign and malignant tumors: high-spectral-resolution diffuse optical spectroscopy. Radiology 2010;254:277-284.

31 Choe R: Diffuse optical tomography and spectroscopy in breast cancer characterization and therapy monitoring at UPENN (invited paper). Conf Proc IEEE Eng Med Biol Soc 2009;1:6335-6337.

- 32 Villalobos V, Naik S, Piwnica-Worms D: Current state of imaging protein-protein interactions in vivo with genetically encoded reporters. Annu Rev Biomed Eng 2007;9: 321-349.

-33 Hoffman RM: The multiple uses of fluorescent proteins to visualize cancer in vivo. Nat Rev Cancer 2005;5:796-806.
4 Hoffman RM: Imaging cancer dynamics in vivo at the tumor and cellular level with fluorescent proteins. Clin Exp Metastasis 2009; 26:345-355.

35 Boppart SA: Optical coherence tomography - principles, applications and advances. Minerva Biotecnol 2004;16:211-237.

36 Zysk AM, Nguyen FT, Oldenburg AL, Marks DL, Boppart SA: Optical coherence tomography: a review of clinical development from bench to bedside. J Biomed Opt 2007;12: 051403.

37 Gibson AP, Hebden JC, Arridge SR: Recent advances in diffuse optical imaging. Phys Med Biol 2005;50:R1-R43.

38 Wang LV, Wu H-I: Biomedical Optics: Principles and Imaging, ed 1. Hoboken, WileyInterscience, 2007.

39 Xu RX, Povoski SP: Diffuse optical imaging and spectroscopy for cancer. Expert Rev Med Devices 2007;4:83-95.

40 Hebden JC, Arridge SR, Delpy DT: Optical imaging in medicine. I. Experimental techniques. Phys Med Biol 1997;42:825-840.

41 Chance B, Nioka S, Kent J, McCully K, Fountain M, Greenfeld R, Holtom G: Time-resolved spectroscopy of hemoglobin and myoglobin in resting and ischemic muscle. Anal Biochem 1988;174:698-707.

42 Grosenick D, Wabnitz H, Rinneberg $\mathrm{HH}$, Moesta KT, Schlag PM: Development of a time-domain optical mammograph and first in vivo applications. Appl Opt 1999;38:29272943.

43 Patwardhan S, Bloch S, Achilefu S, Culver J: Time-dependent whole-body fluorescence tomography of probe bio-distributions in mice. Opt Express 2005;13:2564-2577.

$44 \mathrm{Xu} \mathrm{MH,} \mathrm{Wang} \mathrm{LHV:} \mathrm{Photoacoustic} \mathrm{imaging}$ in biomedicine. Rev Sci Instruments 2006; 77.

45 Arridge SR, Schotland JC: Optical tomography: forward and inverse problems. Inverse Problem 2009;2.

46 Arridge SR, Hebden JC: Optical imaging in medicine. II. Modelling and reconstruction. Phys Med Biol 1997;42:841-853.

47 Arridge SR, Schweiger M: Image reconstruction in optical tomography. Philos Trans $\mathrm{R}$ Soc Lond B Biol Sci 1997;352:717-726.

-48 Dehghani H, Srinivasan S, Pogue BW, Gibson A: Numerical modelling and image reconstruction in diffuse optical tomography. Philos Transact A Math Phys Eng Sci 2009; 367:3073-3093.

49 Wang L, Jacques SL, Zheng L: MCML - Monte Carlo modeling of light transport in multilayered tissues. Comput Methods Programs Biomed 1995;47:131-146.

50 Patterson MS, Chance B, Wilson BC: Time resolved reflectance and transmittance for the non-invasive measurement of tissue optical properties. Appl Opt 1989;28:2331-2336. 1 Gibson A, Dehghani H: Diffuse optical imaging. Philos Transact A Math Phys Eng Sci 2009;367:3055-3072.
2 Schweiger M, Arridge SR, Hiraoka M, Delpy DT: The finite element method for the propagation of light in scattering media: boundary and source conditions. Med Phys 1995; 22:1779-1792.

53 Gaudette RJ, Brooks DH, DiMarzio CA, Kilmer ME, Miller EL, Gaudette T, Boas DA: A comparison study of linear reconstruction techniques for diffuse optical tomographic imaging of absorption coefficient. Phys Med Biol 2000;45:1051-1070.

-54 Schweiger M, Gibson A, Arridge SR: Computational aspects of diffuse optical tomography. Comput Sci Eng 2003;5:33-41.

55 Yalavarthy PK, Pogue BW, Dehghani H, Paulsen KD: Weight-matrix structured regularization provides optimal generalized least-squares estimate in diffuse optical tomography. Med Phys 2007;34:20852098.

56 Yalavarthy PK, Lynch DR, Pogue BW, Dehghani $\mathrm{H}$, Paulsen KD: Implementation of a computationally efficient least-squares algorithm for highly under-determined threedimensional diffuse optical tomography problems. Med Phys 2008;35:1682-1697.

57 Boas DA, Brooks DH, Miller EL, DiMarzio CA, Kilmer M, Gaudette RJ, Zhang Q: Imaging the body with diffuse optical tomography. IEEE Signal Process Mag 2001;18:5775 .

58 Correia T, Gibson A, Schweiger M, Hebden J: Selection of regularization parameter for optical topography. J Biomed Opt 2009;14: 034044

59 Schweiger M, Arridge SR, Nissila I: GaussNewton method for image reconstruction in diffuse optical tomography. Phys Med Biol 2005;50:2365-2386.

60 Ntziachristos V, Turner G, Dunham J, Windsor S, Soubret A, Ripoll J, Shih HA: Planar fluorescence imaging using normalized data. J Biomed Opt 2005; 10:064007.

61 Hyde D, Miller E, Brooks DH, Ntziachristos $\mathrm{V}$ : A statistical approach to inverting the born ratio. IEEE Trans Med Imaging 2007; 26:893-905.

-62 Ntziachristos V, Weissleder R: Experimental three-dimensional fluorescence reconstruction of diffuse media by use of a normalized born approximation. Opt Lett 2001;26:893895

63 Gabor D: A new microscopic principle. Nature 1948;161:777.

64 Srinivasan V, Liu HC, Halioua M: Automated phase-measuring profilometry of 3-D diffuse objects. Appl Opt 1984;23:3105.

65 Gioux S, Mazhar A, Cuccia DJ, Durkin AJ, Tromberg BJ, Frangioni JV: Three-dimensional surface profile intensity correction for spatially modulated imaging. J Biomed Opt 2009; 14:034045

- 66 Takeda M, Mutoh K: Fourier transform profilometry for the automatic measurement of 3-D object shapes. Appl Opt 1983; 22:3977. 
-67 Ramanujam N, Mitchell MF, Mahadevan A, Thomsen S, Silva E, Richards-Kortum R: Fluorescence spectroscopy: a diagnostic tool for cervical intraepithelial neoplasia (CIN). Gynecol Oncol 1994;52:31-38.

68 Richards-Kortum R, Sevick-Muraca E: Quantitative optical spectroscopy for tissue diagnosis. Annu Rev Phys Chem 1996;47:555-606.

-69 Tromberg BJ, Pogue BW, Paulsen KD, Yodh AG, Boas DA, Cerussi AE: Assessing the future of diffuse optical imaging technologies for breast cancer management. Med Phys 2008;35:2443-2451.

-70 Vishwanath K, Klein D, Chang K, Schroeder T, Dewhirst MW, Ramanujam N: Quantitative optical spectroscopy can identify longterm local tumor control in irradiated murine head and neck xenografts. J Biomed Opt 2009;14:054051.

-71 Kukreti S, Cerussi A, Tromberg B, Gratton E: Intrinsic tumor biomarkers revealed by novel double-differential spectroscopic analysis of near-infrared spectra. J Biomed Opt 2007; 12:020509.

-72 Kukreti S, Cerussi A, Tromberg B, Gratton E: Intrinsic near-infrared spectroscopic markers of breast tumors. Dis Markers 2008;25: 281-290.

-73 Vishwanath K, Yuan H, Barry WT, Dewhirst MW, Ramanujam N: Using optical spectroscopy to longitudinally monitor physiological changes within solid tumors. Neoplasia 2009;11:889-900.

74 Palmer GM, Boruta RJ, Viglianti BL, Lan L, Spasojevic I, Dewhirst MW: Non-invasive monitoring of intra-tumor drug concentration and therapeutic response using optical spectroscopy. J Control Release 2010;142: 457-464.

-75 Cerussi AE, Tanamai VW, Mehta RS, Hsiang D, Butler J, Tromberg BJ: Frequent optical imaging during breast cancer neoadjuvant chemotherapy reveals dynamic tumor physiology in an individual patient. Acad Radiol 2010;17:1031-1039.

-76 Choe R, Konecky SD, Corlu A, Lee K, Durduran T, Busch DR, Pathak S, Czerniecki BJ, Tchou J, Fraker DL, Demichele A, Chance B, Arridge SR, Schweiger M, Culver JP, Schnall MD, Putt ME, Rosen MA, Yodh AG: Differentiation of benign and malignant breast tumors by in-vivo three-dimensional parallelplate diffuse optical tomography. J Biomed Opt 2009; 14:024020.

-77 Patwardhan SV, Bloch S, Achilefu S, Culver JP: Quantitative small animal fluorescence tomography using an ultrafast gated image intensifier. Conf Proc IEEE Eng Med Biol Soc 2006; 1:2675-2678.

78 Patwardhan SV, Culver JP: Quantitative diffuse optical tomography for small animals using an ultrafast gated image intensifier. J Biomed Opt 2008;13:011009.

-79 Ntziachristos V, Tung CH, Bremer C, Weissleder R: Fluorescence molecular tomography resolves protease activity in vivo. Nat Med 2002;8:757-760.
80 Ntziachristos V, Bremer C, Weissleder R: Fluorescence imaging with near-infrared light: new technological advances that enable in vivo molecular imaging. Eur Radiol 2003;13:195-208.

81 Pogue BW, Gibbs SL, Chen B, Savellano M: Fluorescence imaging in vivo: raster scanned point-source imaging provides more accurate quantification than broad beam geometries. Technol Cancer Res Treat 2004;3:15-21.

82 Berezin MY, Lee H, Akers W, Guo K, Goiffon RJ, Almutairi A, Frechet JM, Achilefu S: Engineering NIR dyes for fluorescent lifetime contrast. Conf Proc IEEE Eng Med Biol Soc 2009;1:114-117.

-83 Nothdurft RE, Patwardhan SV, Akers W, Ye Y, Achilefu S, Culver JP: In vivo fluorescence lifetime tomography. J Biomed Opt 2009;14: 024004.

84 Bloch S, Lesage F, McIntosh L, Gandjbakhche A, Liang K, Achilefu S: Whole-body fluorescence lifetime imaging of a tumortargeted near-infrared molecular probe in mice. J Biomed Opt 2005; 10:054003.

85 Berezin MY, Achilefu S: Fluorescence lifetime measurements and biological imaging. Chem Rev 2010;110:2641-2684.

86 Berezin MY, Lee H, Akers W, Nikiforovich G, Achilefu S: Ratiometric analysis of fluorescence lifetime for probing binding sites in albumin with near-infrared fluorescent molecular probes. Photochem Photobiol 2007; 83:1371-1378.

87 Cubeddu R, Canti G, Taroni P, Valentini G: Time-gated fluorescence imaging for the diagnosis of tumors in a murine model. Photochem Photobiol 1993;57:480-485.

88 Cubeddu R, Canti G, Pifferi A, Taroni P, Valentini G: Fluorescence lifetime imaging of experimental tumors in hematoporphyrin derivative-sensitized mice. Photochem Photobiol 1997;66:229-236.

89 Andersson-Engels S, Canti G, Cubeddu R, Eker C, af Klinteberg C, Pifferi A, Svanberg K, Svanberg S, Taroni P, Valentini G, Wang I: Preliminary evaluation of two fluorescence imaging methods for the detection and the delineation of basal cell carcinomas of the skin. Lasers Surg Med 2000;26:76-82.

90 Reynolds JS, Troy TL, Mayer RH, Thompson AB, Waters DJ, Cornell KK, Snyder PW, Sevick-Muraca EM: Imaging of spontaneous canine mammary tumors using fluorescent contrast agents. Photochem Photobiol 1999; 70:87-94.

91 Akers W, Lesage F, Holten D, Achilefu S: In vivo resolution of multiexponential decays of multiple near-infrared molecular probes by fluorescence lifetime-gated whole-body time-resolved diffuse optical imaging. Mol Imaging 2007;6:237-246.

92 Raymond SB, Boas DA, Bacskai BJ, Kumar AT: Lifetime-based tomographic multiplexing. J Biomed Opt 2010;15:046011.

93 Maslov K, Stoica G, Wang LV: In vivo darkfield reflection-mode photoacoustic microscopy. Opt Lett 2005;30:625-627.
94 Zhang HF, Maslov K, Wang LV: In vivo imaging of subcutaneous structures using functional photoacoustic microscopy. Nat Protoc 2007;2:797-804.

-95 Li ML, Zhang HE, Maslov K, Stoica G, Wang LV: Improved in vivo photoacoustic microscopy based on a virtual-detector concept. Opt Lett 2006;31:474-476.

$\$ 96$ Kim C, Favazza C, Wang LV: In vivo photoacoustic tomography of chemicals: highresolution functional and molecular optical imaging at new depths. Chem Rev 2010; 110:2756-2782.

-97 Kim G, Huang SW, Day KC, O’Donnell M, Agayan RR, Day MA, Kopelman R, Ashkenazi S: Indocyanine-green-embedded pebbles as a contrast agent for photoacoustic imaging. J Biomed Opt 2007; 12:044020.

98 Homan K, Kim S, Chen YS, Wang B, Mallidi S, Emelianov S: Prospects of molecular photoacoustic imaging at $1064 \mathrm{~nm}$ wavelength. Opt Lett 2010;35:2663-2665.

99 Achilefu SI, Bornhop DJ, Raghavachari R: Society of Photo-optical Instrumentation Engineers: Optical Molecular Probes for Biomedical Applications, San Jose, January 2006. Bellingham, SPIE, 2006.

100 Akers WJ, Kim C, Berezin M, Guo K, Fuhrhop R, Lanza GM, Fischer GM, Daltrozzo E, Zumbusch A, Cai X, Wang LV, Achilefu S: Noninvasive photoacoustic and fluorescence sentinel lymph node identification using dye-loaded perfluorocarbon nanoparticles. ACS Nano 2011;25:173-182.

101 Pramanik M, Ku G, Li C, Wang LV: Design and evaluation of a novel breast cancer detection system combining both thermoacoustic (TA) and photoacoustic (PA) tomography. Med Phys 2008;35:2218-2223.

102 Manohar S, Kharine A, van Hespen JC, Steenbergen W, van Leeuwen TG: Photoacoustic mammography laboratory prototype: imaging of breast tissue phantoms. J Biomed Opt 2004;9:1172-1181.

103 Kim C, Erpelding TN, Maslov K, Jankovic L, Akers WJ, Song LA, Achilefu S, Margenthaler JA, Pashley MD, Wang LHV: Handheld array-based photoacoustic probe for guiding needle biopsy of sentinel lymph nodes. J Biomed Opt 2010;15:046010.

104 Galanzha EI, Kokoska MS, Shashkov EV, Kim JW, Tuchin VV, Zharov VP: In vivo fiber-based multicolor photoacoustic detection and photothermal purging of metastasis in sentinel lymph nodes targeted by nanoparticles. J Biophotonics 2009;2:528539.

105 Staley J, Grogan P, Samadi AK, Cui H, Cohen MS, Yang X: Growth of melanoma brain tumors monitored by photoacoustic microscopy. J Biomed Opt 2010;15: 040510.

106 Pan D, Pramanik M, Senpan A, Allen JS, Zhang $\mathrm{H}$, Wickline SA, Wang LV, Lanza GM: Molecular photoacoustic imaging of angiogenesis with integrin-targeted gold nanobeacons. FASEB J 2011;25:875-882. 
- 107 Jose J, Manohar S, Kolkman RGM, Steenbergen W, van Leeuwen TG: Imaging of tumor vasculature using Twente photoacoustic systems. J Biophotonics 2009;2:701-717.

108 Galanzha EI, Shashkov EV, Spring PM, Suen JY, Zharov VP: In vivo, noninvasive, label-free detection and eradication of circulating metastatic melanoma cells using two-color photoacoustic flow cytometry with a diode laser. Cancer Res 2009;69: 7926-7934.

109 Olafsson R, Bauer DR, Montilla LG, Witte RS: Real-time, contrast enhanced photoacoustic imaging of cancer in a mouse window chamber. Opt Express 2010;18:1862518632.

- 110 Kim C, Cho EC, Chen J, Song KH, Au L, Favazza C, Zhang Q, Cobley CM, Gao F, Xia Y, Wang LV: In vivo molecular photoacoustic tomography of melanomas targeted by bioconjugated gold nanocages. ACS Nano 2010;4:4559-4564.

- 111 Song L, Kim C, Maslov K, Shung KK, Wang LV: High-speed dynamic 3D photoacoustic imaging of sentinel lymph node in a murine model using an ultrasound array. Med Phys 2009;36:3724-3729.

- 112 Song KH, Kim C, Maslov K, Wang LV: Noninvasive in vivo spectroscopic nanorodcontrast photoacoustic mapping of sentinel lymph nodes. Eur J Radiol 2009;70:227-231.

-113 Song KH, Stein EW, Margenthaler JA, Wang LV: Noninvasive photoacoustic identification of sentinel lymph nodes containing methylene blue in vivo in a rat model. J Biomed Opt 2008;13:054033.

- 114 Pramanik M, Song KH, Swierczewska M, Green D, Sitharaman B, Wang LV: In vivo carbon nanotube-enhanced non-invasive photoacoustic mapping of the sentinel lymph node. Phys Med Biol 2009;54:32913301.

- 115 Galanzha EI, Shashkov EV, Kelly T, Kim JW, Yang L, Zharov VP: In vivo magnetic enrichment and multiplex photoacoustic detection of circulating tumour cells. Nat Nanotechnol 2009;4:855-860.

-116 Leff DR, Warren OJ, Enfield LC, Gibson A, Athanasiou T, Patten DK, Hebden J, Yang GZ, Darzi A: Diffuse optical imaging of the healthy and diseased breast: a systematic review. Breast Cancer Res Treat 2008; 108: 9-22.

-117 Monici M: Cell and tissue autofluorescence research and diagnostic applications. Biotechnol Annu Rev 2005;11:227-256.

- 118 Zhu C, Palmer GM, Breslin TM, Harter J, Ramanujam N: Diagnosis of breast cancer using fluorescence and diffuse reflectance spectroscopy: a Monte-Carlo-model-based approach. J Biomed Opt 2008;13:034015.

119 Imaeda H, Hosoe N, Kashiwagi K, Ida Y, Saito Y, Suzuki H, Aiura K, Ogata H, Kumai K, Hibi T: Autofluorescence videoendoscopy system using the SAFE-3000 for assessing superficial gastric neoplasia. J Gastroenterol Hepatol 2010;25:706-711.
120 Falk GW: Autofluorescence endoscopy. Gastrointest Endosc Clin N Am 2009;19: 209-220.

121 Bhaumik S, Depuy J, Klimash J: Strategies to minimize background autofluorescence in live mice during noninvasive fluorescence optical imaging. Lab Anim 2007;36: 40-43.

122 Bouchard MB, MacLaurin SA, Dwyer PJ, Mansfield J, Levenson R, Krucker T: Technical considerations in longitudinal multispectral small animal molecular imaging. J Biomed Opt 2007;12:051601.

123 Akers WJ, Achilefu S: Optical molecular imaging; in Boas DA, Pitris C, Ramanujam N (eds): Handbook of Biomedical Optics. Boca Raton, CRC Press, 2010.

124 Licha K, Hessenius C, Becker A, Henklein P, Bauer M, Wisniewski S, Wiedenmann B, Semmler W: Synthesis, characterization, and biological properties of cyanine-labeled somatostatin analogues as receptortargeted fluorescent probes. Bioconjug Chem 2001;12:44-50.

125 Licha K, Riefke B, Ntziachristos V, Becker A, Chance B, Semmler W: Hydrophilic cyanine dyes as contrast agents for near-infrared tumor imaging: synthesis, photophysical properties and spectroscopic in vivo characterization. Photochem Photobiol 2000;72:392-398

126 Intes X, Ripoll J, Chen Y, Nioka S, Yodh AG, Chance B: In vivo continuous-wave optical breast imaging enhanced with indocyanine green. Med Phys 2003;30:1039-1047.

127 Alacam B, Yazici B, Intes X, Chance B: Analysis of ICG Pharmacokinetics in Cancerous Tumors using NIR Optical Methods. Conf Proc IEEE Eng Med Biol Soc 2005;1:62-65.

128 Alacam B, Yazici B, Intes X, Nioka S, Chance B: Pharmacokinetic-rate images of indocyanine green for breast tumors using near-infrared optical methods. Phys Med Biol 2008;53:837-859.

129 Sevick-Muraca EM, Sharma R, Rasmussen JC, Marshall MV, Wendt JA, Pham HQ, Bonefas E, Houston JP, Sampath L, Adams KE, Blanchard DK, Fisher RE, Chiang SB, Elledge R, Mawad ME: Imaging of lymph flow in breast cancer patients after microdose administration of a near-infrared fluorophore: feasibility study. Radiology 2008; 246:734-741.

130 Ludwig JA, Weinstein JN: Biomarkers in cancer staging, prognosis and treatment selection. Nat Rev Cancer 2005;5:845856.

131 Sidransky D: Emerging molecular markers of cancer. Nat Rev Cancer 2002;2:210-219.

132 Achilefu S, Dorshow RB, Bugaj JE, Rajagopalan R: Novel receptor-targeted fluorescent contrast agents for in vivo tumor imaging. Invest Radiol 2000;35:479-485.

133 Ballou B, Fisher GW, Deng JS, Hakala TR, Srivastava M, Farkas DL: Cyanine fluorochrome-labeled antibodies in vivo: assess- ment of tumor imaging using $\mathrm{Cy} 3$, Cy5, Cy5.5, and Cy7. Cancer Detect Prev 1998; 22:251-257.

134 Clauss MA, Jain RK: Interstitial transport of rabbit and sheep antibodies in normal and neoplastic tissues. Cancer Res 1990;50: 3487-3492.

135 Ross JS, Fletcher JA: HER-2/neu (c-erb-B2) gene and protein in breast cancer. Am J Clin Pathol 1999;112(suppl 1):S53-S67.

136 Ross JS, Fletcher JA, Bloom KJ, Linette GP, Stec J, Symmans WF, Pusztai L, Hortobagyi GN: Targeted therapy in breast cancer: the HER-2/neu gene and protein. Mol Cell Proteomics 2004;3:379-398.

137 Nicholson S, Richard J, Sainsbury C, Halcrow P, Kelly P, Angus B, Wright C, Henry J, Farndon JR, Harris AL: Epidermal growth factor receptor (EGFR): results of a 6 year follow-up study in operable breast cancer with emphasis on the node negative subgroup. Br J Cancer 1991;63:146-150.

138 Cobleigh MA, Vogel CL, Tripathy D, Robert NJ, Scholl S, Fehrenbacher L, Wolter JM, Paton V, Shak S, Lieberman G, Slamon DJ: Multinational study of the efficacy and safety of humanized anti-HER2 monoclonal antibody in women who have HER2-overexpressing metastatic breast cancer that has progressed after chemotherapy for metastatic disease. J Clin Oncol 1999;17:2639-2648.

139 Ross JS, Fletcher JA, Bloom KJ, Linette GP, Stec J, Clark E, Ayers M, Symmans WF, Pusztai L, Hortobagyi GN: HER-2/neu testing in breast cancer. Am J Clin Pathol 2003; 120(suppl):S53-S71.

140 Vogel C, Cobleigh MA, Tripathy D, Gutheil JC, Harris LN, Fehrenbacher L, Slamon DJ, Murphy M, Novotny WF, Burchmore M, Shak S, Stewart SJ: First-line, single-agent herceptin (trastuzumab) in metastatic breast cancer: a preliminary report. Eur J Cancer 2001;37(suppl 1):S25-S29.

141 Koyama Y, Hama Y, Urano Y, Nguyen DM, Choyke PL, Kobayashi H: Spectral fluorescence molecular imaging of lung metastases targeting HER2/neu. Clin Cancer Res 2007; 13:2936-2945.

142 Sampath L, Kwon S, Hall MA, Price RE, Sevick-Muraca EM: Detection of cancer metastases with a dual-labeled near-infrared/ positron emission tomography imaging agent. Transl Oncol 2010;3:307-317.

143 Achilefu S, Jimenez HN, Dorshow RB, Bugaj JE, Webb EG, Wilhelm RR, Rajagopalan R, Johler J, Erion JL: Synthesis, in vitro receptor binding, and in vivo evaluation of fluorescein and carbocyanine peptidebased optical contrast agents. J Med Chem 2002;45:2003-2015.

144 Giancotti FG: Complexity and specificity of integrin signalling. Nat Cell Biol 2000; 2:E13-E14.

145 Giancotti FG: Integrin signaling: specificity and control of cell survival and cell cycle progression. Curr Opin Cell Biol 1997;9: 691-700. 
146 Giancotti FG, Ruoslahti E: Transductionintegrin signaling. Science 1999;285:10281032.

147 Guo WJ, Giancotti FG: Integrin signalling during tumour progression. Nat Rev Mol Cell Biol 2004;5:816-826.

148 Pierschbacher MD, Ruoslahti E: Cell attachment activity of fibronectin can be duplicated by small synthetic fragments of the molecule. Nature 1984;309:30-33.

-149 Haubner R, Weber WA, Beer AJ, Vabuliene E, Reim D, Sarbia M, Becker KF, Goebel M, Hein R, Wester HJ, Kessler H, Schwaiger M: Noninvasive visualization of the activated alphavbeta 3 integrin in cancer patients by positron emission tomography and $[18 \mathrm{~F}]$ galacto-RGD. PLoS Med 2005;2:e70.

150 Achilefu S, Bloch S, Markiewicz MA, Zhong T, Ye Y, Dorshow RB, Chance B, Liang K: Synergistic effects of light-emitting probes and peptides for targeting and monitoring integrin expression. Proc Natl Acad Sci USA 2005;102:7976-7981.

151 Bloch S, Xu B, Ye Y, Liang K, Nikiforovich GV, Achilefu S: Targeting beta-3 integrin using a linear hexapeptide labeled with a near-infrared fluorescent molecular probe. Mol Pharm 2006;3:539-549.

152 Ye Y, Bloch S, Xu B, Achilefu S: Design, synthesis, and evaluation of near infrared fluorescent multimeric RGD peptides for targeting tumors. J Med Chem 2006;49:22682275.

153 Hsiung PL, Hardy J, Friedland S, Soetikno R, Du CB, Wu AP, Sahbaie P, Crawford JM, Lowe AW, Contag CH, Wang TD: Detection of colonic dysplasia in vivo using a targeted heptapeptide and confocal microendoscopy. Nat Med 2008; 14:454-458.

-154 Lee H, Akers WJ, Cheney PP, Edwards WB, Liang K, Culver JP, Achilefu S: Complementary optical and nuclear imaging of caspase-3 activity using combined activatable and radio-labeled multimodality molecular probe. J Biomed Opt 2009; 14: 040507.

-155 McIntyre JO, Matrisian LM: Molecular imaging of proteolytic activity in cancer. J Cell Biochem 2003;90:1087-1097.

156 McIntyre JO, Matrisian LM: Optical proteolytic beacons for in vivo detection of matrix metalloproteinase activity. Methods Mol Biol 2009;539:155-174.

- 157 McIntyre JO, Scherer RL, Matrisian LM: Near-infrared optical proteolytic beacons for in vivo imaging of matrix metalloproteinase activity. Methods Mol Biol 2010; 622:279-304.

158 Zhang Z, Fan J, Cheney PP, Berezin MY, Edwards WB, Akers WJ, Shen D, Liang K, Culver JP, Achilefu S: Activatable molecular systems using homologous near-infrared fluorescent probes for monitoring enzyme activities in vitro, in cellulo, and in vivo. Mol Pharm 2009;6:416-427.
159 Paulick MG, Bogyo M: Application of activity-based probes to the study of enzymes involved in cancer progression. Curr Opin Genet Dev 2008;18:97-106.

160 Himelstein BP, Canete-Soler R, Bernhard EJ, Dilks DW, Muschel RJ: Metalloproteinases in tumor progression: the contribution of MMP-9. Invasion Metastasis 1994-1995; 14:246-258.

161 Fingleton B: Matrix metalloproteinase inhibitors for cancer therapy: the current situation and future prospects. Expert Opin Ther Targets 2003;7:385-397.

162 Duffy MJ: Proteases as prognostic markers in cancer. Clin Cancer Res 1996;2:613-618.

163 Liotta LA, Thorgeirsson UP, Garbisa S: Role of collagenases in tumor cell invasion. Cancer Metastasis Rev 1982;1:277-288.

164 Weissleder R, Tung CH, Mahmood U, Bogdanov A Jr: In vivo imaging of tumors with protease-activated near-infrared fluorescent probes. Nat Biotechnol 1999;17:375-378.

165 Bremer C, Bredow S, Mahmood U, Weissleder R, Tung CH: Optical imaging of matrix metalloproteinase-2 activity in tumors: feasibility study in a mouse model. Radiology 2001;221:523-529.

166 Bremer C, Tung CH, Weissleder R: In vivo molecular target assessment of matrix metalloproteinase inhibition. Nat Med 2001;7: 743-748.

167 Blum G, von Degenfeld G, Merchant MJ, Blau HM, Bogyo M: Noninvasive optical imaging of cysteine protease activity using fluorescently quenched activity-based probes. Nat Chem Biol 2007;3:668-677.

168 Gocheva V, Zeng W, Ke DX, Klimstra D, Reinheckel T, Peters C, Hanahan D, Joyce JA: Distinct roles for cysteine cathepsin genes in multistage tumorigenesis. Genes Dev 2006;20:543-556.

169 Odonkor CA, Achilefu S: Differential activity of caspase-3 regulates susceptibility of lung and breast tumor cell lines to paclitaxel. Open Biochem J 2008;2:121-128.

170 Odonkor CA, Achilefu S: Modulation of effector caspase cleavage determines response of breast and lung tumor cell lines to chemotherapy. Cancer Invest 2009;27:417429.

171 Bullok K, Piwnica-Worms D: Synthesis and characterization of a small, membranepermeant, caspase-activatable far-red fluorescent peptide for imaging apoptosis. J Med Chem 2005;48:5404-5407.

172 Bullok KE, Maxwell D, Kesarwala AH, Gammon S, Prior JL, Snow M, Stanley S, Piwnica-Worms D: Biochemical and in vivo characterization of a small, membrane-permeant, caspase-activatable farred fluorescent peptide for imaging apoptosis. Biochemistry 2007;46:4055-4065.

173 Ntziachristos V, Yodh AG, Schnall MD, Chance B: MRI-guided diffuse optical spectroscopy of malignant and benign breast lesions. Neoplasia 2002;4:347-354.
174 Zhu Q, Kurtzma SH, Hegde P, Tannenbaum S, Kane M, Huang M, Chen NG, Jagjivan B, Zarfos K: Utilizing optical tomography with ultrasound localization to image heterogeneous hemoglobin distribution in large breast cancers. Neoplasia 2005;7: 263-270.

175 McCann CM, Waterman P, Figueiredo JL, Aikawa E, Weissleder R, Chen JW: Combined magnetic resonance and fluorescence imaging of the living mouse brain reveals glioma response to chemotherapy. Neuroimage 2009;45:360-369.

176 Zhu Q, Tannenbaum S, Kurtzman SH: Optical tomography with ultrasound localization for breast cancer diagnosis and treatment monitoring. Surg Oncol Clin N Am 2007;16:307-321.

177 Gulsen G, Yu H, Wang J, Nalcioglu O, Merritt S, Bevilacqua F, Durkin AJ, Cuccia DJ, Lanning R, Tromberg BJ: Congruent MRI and near-infrared spectroscopy for functional and structural imaging of tumors. Technol Cancer Res Treat 2002;1:497-505.

178 Culver J, Akers W, Achilefu S: Multimodality molecular imaging with combined optical and SPECT/PET modalities. J Nucl Med 2008;49:169-172.

179 Zhang Q, Brukilacchio TJ, Li A, Stott JJ, Chaves T, Hillman E, Wu T, Chorlton M, Rafferty E, Moore RH, Kopans DB, Boas DA: Coregistered tomographic X-ray and optical breast imaging: initial results. J Biomed Opt 2005;10:024033.

-180 Edwards WB, Akers WJ, Ye Y, Cheney PP, Bloch S, Xu B, Laforest R, Achilefu S: Multimodal imaging of integrin receptor-positive tumors by bioluminescence, fluorescence, gamma scintigraphy, and singlephoton emission computed tomography using a cyclic RGD peptide labeled with a near-infrared fluorescent dye and a radionuclide. Mol Imaging 2009;8:101-110.

181 Berezin MY, Guo K, Teng B, Edwards WB, Anderson CJ, Vasalatiy O, Gandjbakhche A, Griffiths GL, Achilefu S: Radioactivity-synchronized fluorescence enhancement using a radionuclide fluorescencequenched dye. J Am Chem Soc 2009;131: 9198-9200.

182 Guo K, Berezin MY, Zheng J, Akers W, Lin F, Teng B, Vasalatiy O, Gandjbakhche A, Griffiths GL, Achilefu S: Near infrared-fluorescent and magnetic resonance imaging molecular probe with high $\mathrm{T} 1$ relaxivity for in vivo multimodal imaging. Chem Commun (Camb) 2010;46:3705-3707.

183 Li A, Miller EL, Kilmer ME, Brukilacchio TJ, Chaves T, Stott J, Zhang Q, Wu T, Chorlton M, Moore RH, Kopans DB, Boas DA: Tomographic optical breast imaging guided by three-dimensional mammography. Appl Opt 2003;42:5181-5190. 